\title{
Analysis of Two Bronze Mirrors With Tin-rich Surface
}

\section{Zhihui Yao}

Zhengzhou University

Jiatian Zhao ( $18435203368 @ 163 . c o m$ )

Zhengzhou University

\section{Xinguang Wang}

Henan Provincial Institute of Cultural Heritage and Archaeology

\section{Research article}

Keywords: bronze mirror, lacquer, tin-rich layer, natural corrosion, pewter amalgam

Posted Date: December 1st, 2020

DOl: https://doi.org/10.21203/rs.3.rs-114203/v1

License: (1) This work is licensed under a Creative Commons Attribution 4.0 International License. Read Full License 


\title{
Analysis of two bronze mirrors with tin-rich surface
}

\section{Zhihui Yao ${ }^{1}$ Jiatian Zhao ${ }^{1^{*}} \quad$ Xinguang Wang $^{2}$}

\begin{abstract}
"black lacquer " and "silver lacquer"are very special categories of ancient chinese bronze mirrors, and the cause of the formation of lacquer surface has attracted much attention.

In this paper, metallographic microscope, scanning electron microscope are used to analyze one "black lacquer " and one "silver lacquer"bronze mirror. The matrix of the two mirrors is copper-tin alloy with lead and the metallographic structure is as cast. The tin-rich layer with uneven thickness exists on the surface of the 2 mirrors. Based on the analysis of tin-rich layer, it is concluded that the "silver lacquer" is intentionally artificial, and its surface is treated with lead-tin amalgam, which is composed of mechanical combination and micro-metallurgy. The "black paint" was formed by natural corrosion in the underground environment.
\end{abstract}

Key words: bronze mirror, lacquer ,tin-rich layer, natural corrosion,pewter amalgam

\section{Introduction}

Among the bronze mirrors in ancient China, some were widely concerned because of their unique surface morphology, such as the "silver lacquer" mirror (Fig. 1) and the "black lacquer" mirror (Fig. 2). The former describes a phenomenon in which the surface of a bronze mirror is silvery and shiny. The latter has a shiny black surface and a smooth, glittering sense of jade.

"1acquer" this name has appeared in the Song Dynasty [1]. There are a variety of different terms about the " lacquer ", such as "Black lacquer", "Water Patina", "Noble Patina", "Tin-rich layer" and so on[2-5]。

\footnotetext{
*Correspondence: 18435203368@163.com

1 School of History, Zhengzhou University, 100 Science Road, Zhengzhou 450000, People’ s Republic of China. Full list of author information is available at the end of the article
} 


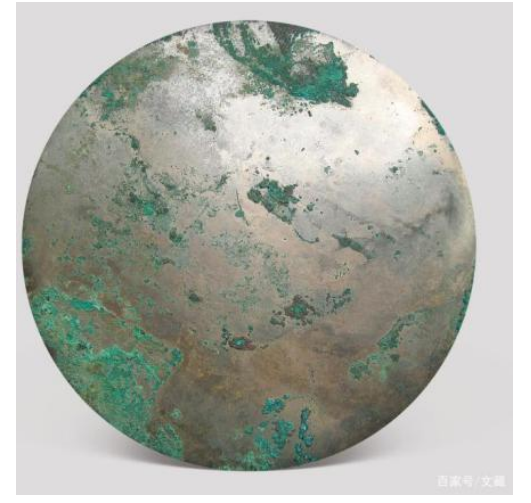

Fig. 1 “silver lacquer” mirror

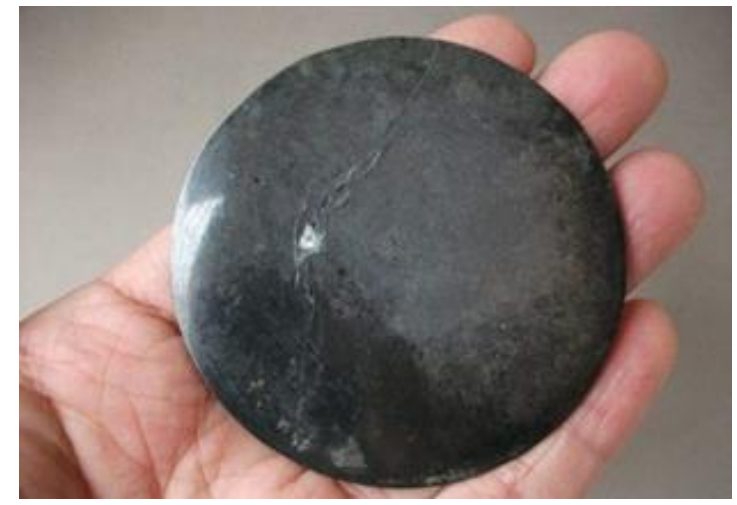

Fig. 2 “Black lacquer” mirror

These kinds of bronze mirrors have good corrosion resistance, and tin-rich layer exists on the surface. There are different views on the formation mechanism of tin rich layers.

About the formation of "silver lacquer", the views can be divided into two kinds: One is that it was artificially treated; the other is artificial treatment + natural corrosion. There are many views on manual treatment, including the theory of tin amalgam process [6] similar to gold gilding; using mirror grinding medicine [7-9]; and mixing tin-rich copper powder with mercury, then by coating and hot plating to form the tin-rich surface of mirror $[10,11]$. The latter is mainly affected by natural corrosion[12].

At present, there are mainly three opinions on the formation of "black lacquer ". First, the artificial treatment [13-15]; The second is natural corrosion theory [16-23]; and the third is artificial treatment + natural corrosion [24,25].

The two bronze mirrors analyzed in the article, one was unearthed from a Han tomb in Wangchenzhai Village, Henan Province, and the other was unearthed from a site in Xianghe Township, Henan Province. Two pieces of bronze mirror with "lacquer " (Fig. 3 and Fig. 4) provide first-hand information for studying the tin rich layer in the mirror. It is helpful for us to better understand the formation mechanism of "lacquer" on the surface from the analysis of structure, shape, composition and so on.
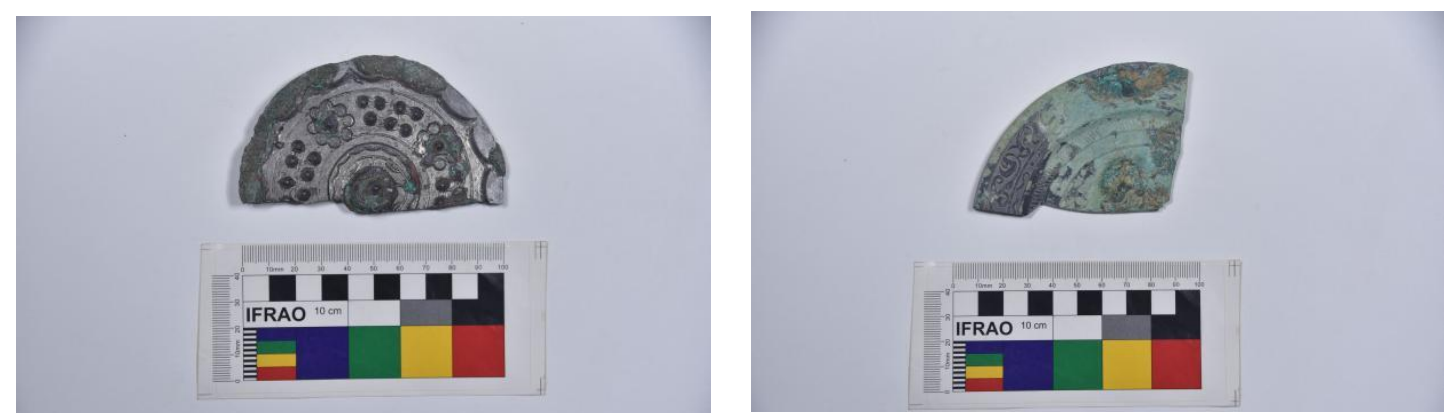


\section{Materials and methods}

\section{Sample}

2 cross section samples were studied in this paper, which were taken from the debris (Fig. 3 and Fig. 4) which excavated from the Han Dynasty Ruins, and then processed by inlay, grinding, polishing, erosion, etc.

\section{Microscopic analysis}

Organizational observed under LEICA DM6000M metallographic microscope.

More detailed morphological observation was obtained by secondary electron imaging and backscattered electron imaging under SEM with a FEI QUANTA-650 equipment.

\section{SEM-EDS analysis}

Component analysis of different parts was carried out by using SEM-EDS, above FEI QUANTA - 650, with APOLLO - X energy spectrometer at 25kV, $100 \mu \mathrm{A}, 10 \mathrm{~mm}$ working distance for 50 seconds acquisition.

\section{Results and discussions}

\section{Morphology analysis}

1. the sample with silver lacquer

The matrix consists of $a+(a+\delta)$ eutectoid (Fig. 5 left and Fig. 6 left), The a phase is irregularly distributed on the eutectoid in needle bar or island shape. Lead particles were dispersed. The porosity of the casting, free copper and a small amount of sulfide can be observed occasionally. The matrix was in the as-cast state and showed no trace of heat homogenization. There are two layers outside the matrix. The outermost layer, which is very thin and the transition layer between the matrix and the outermost layer, which is thicker. Their metallographic structures are difficult to observe under a metallographic microscope (Fig. 5 right). At a larger multiple under SEM, It was observed that there was no trace of heat homogenization and the lead particles were mostly deposited in the loose position 
(Fig. 6 left). There is no obvious interface between the transition layer and the matrix, and each layer has fusion diffusion. The thickness of the outermost layer was less than $10 \mu \mathrm{m}$ and the thickness of the transition layer ranged from $20 \sim$ $50 \mu \mathrm{m}$ (Fig. 6 right).
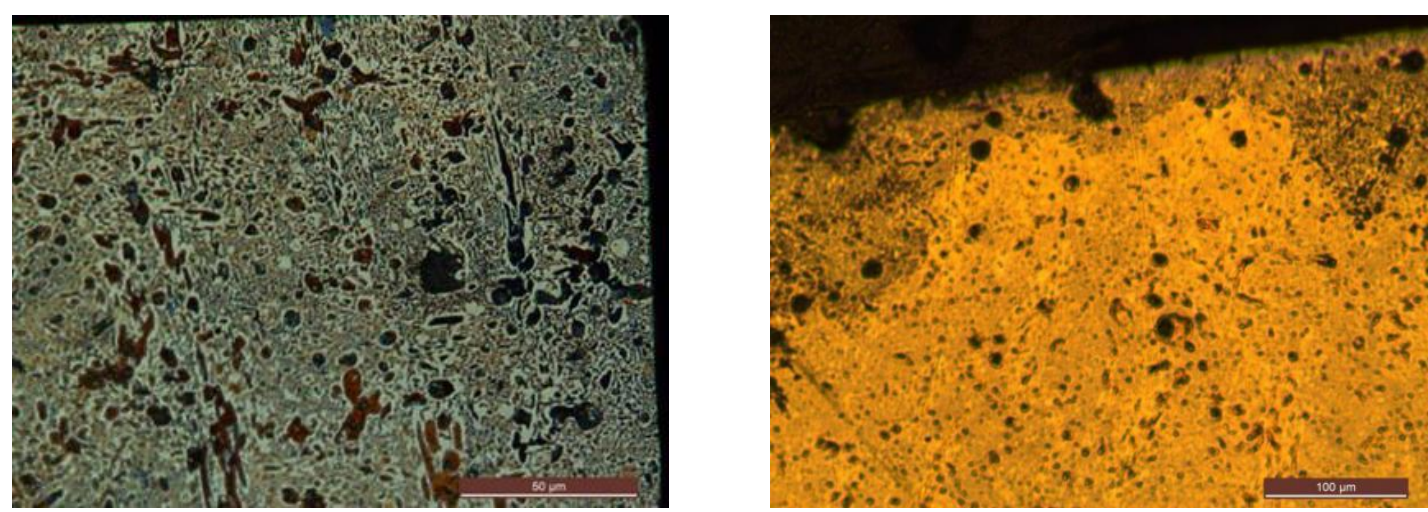

Fig. 5 metallograph (left: matrix; right: matrix and the surface layers)
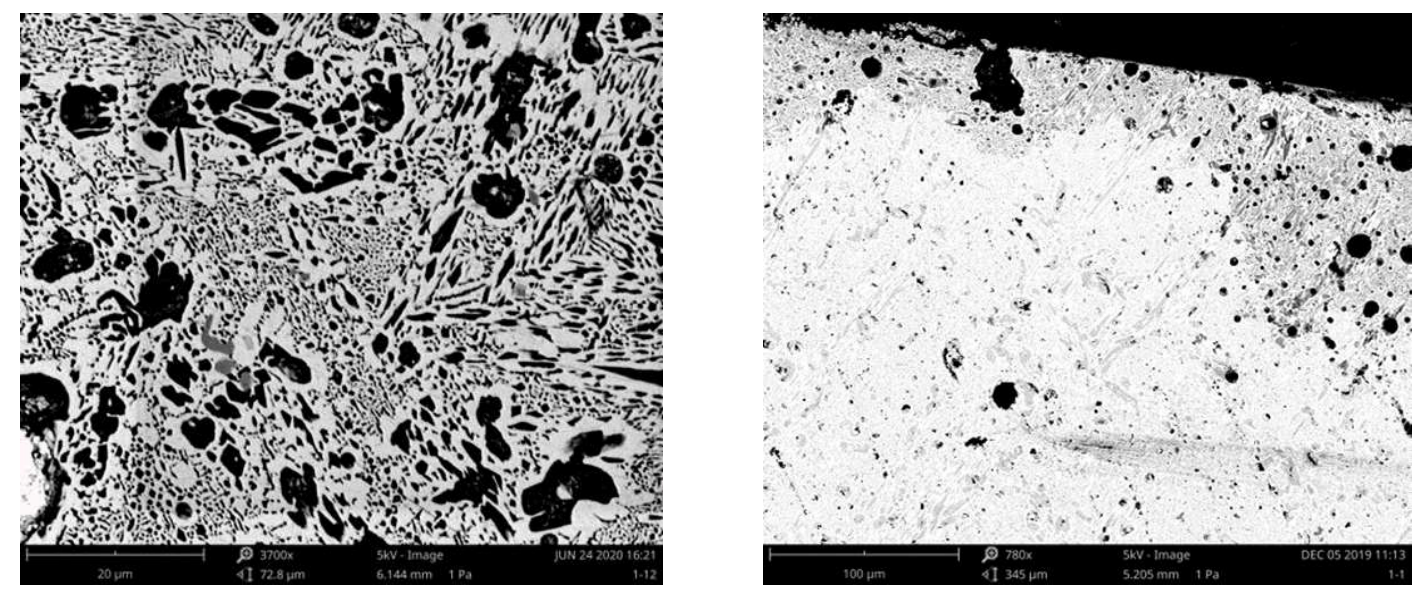

Fig. 6 backscattered electron imaging (left: matrix; right: matrix and surface layers)

2. the sample with black lacquer

The matrix consists of $a+(a+\delta)$ eutectoid and the matrix is as-cast without any trace of heat homogenization(Fig. 7 left). The backscattered electron imaging is consistent with the metallographic results. Lead particles are uniformly dispersed in the matrix (Fig. 7 right). There are two layers outside the matrix. The outermost layer is the most corrosive. The transition layer between the matrix and the outermost layer, in which a phase was corrode d first(Fig. 8 left). The thickness of the outermost layer was $5 \sim 10 \mu \mathrm{m}$ and the transition layer ranged from50 $100 \mu \mathrm{m}$. Under the backscattered electron images, the number of lead from the matrix to the outermost layer was observed to decrease gradually(Fig. 8 right). 

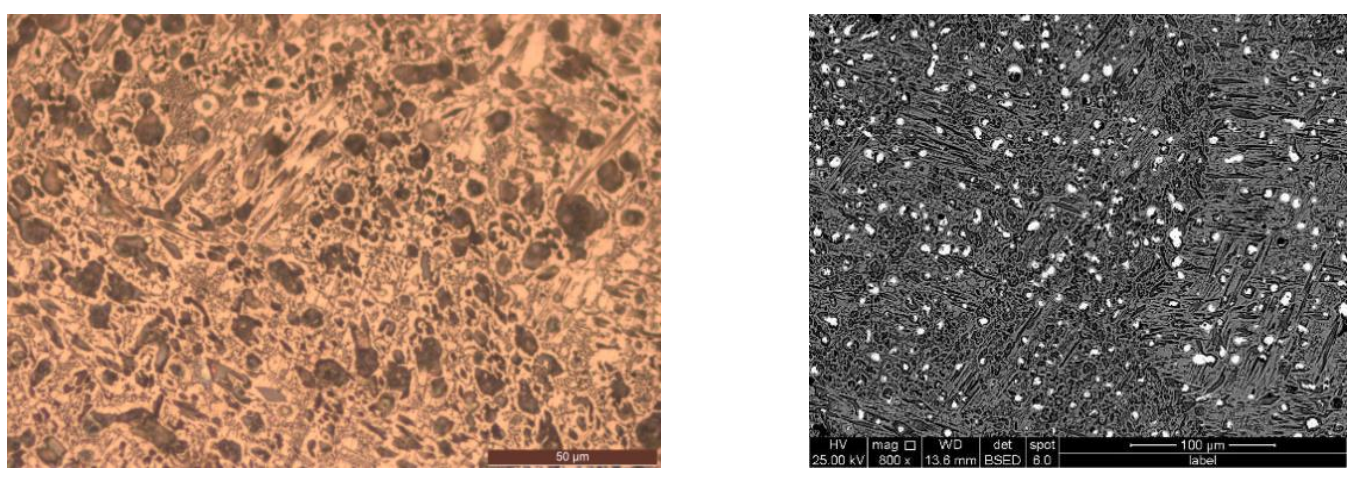

Fig. 7 the matrix (left:metallographic; right:backscattered electron imaging)
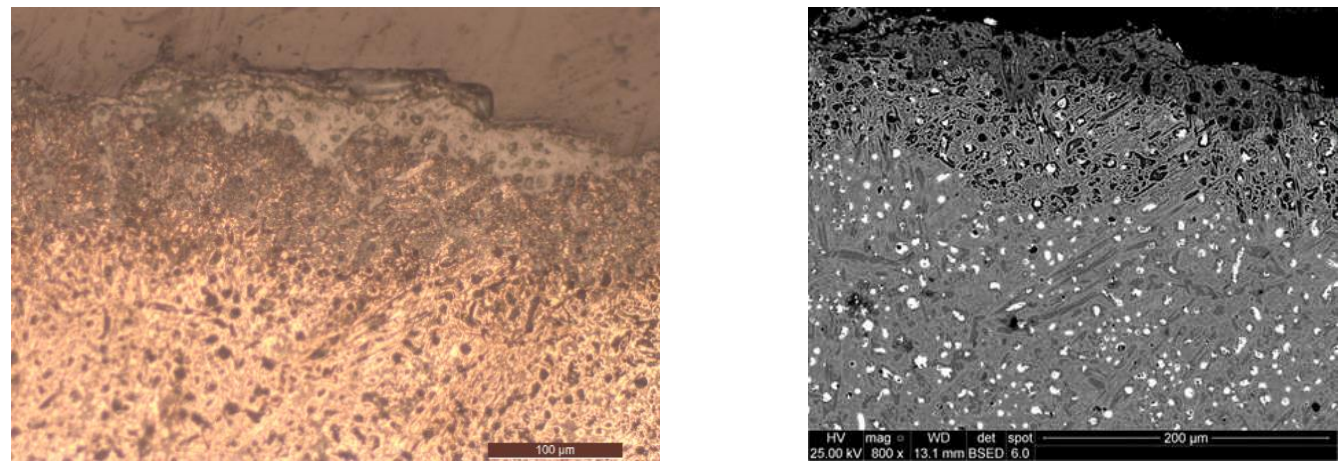

Fig. 8 the matrix and surface layers (left:metallographic ; right: backscattered electron imaging )

\section{Component analysis}

Above 2 samples were analyzed by SEM-EDS. EDS results of different positions shown in Table 1 and Table 2, Three random areas were selected for analysis. The scans were taken three times and the mean values were obtained.

Table 1 EDS results for the sample with silver lacquer

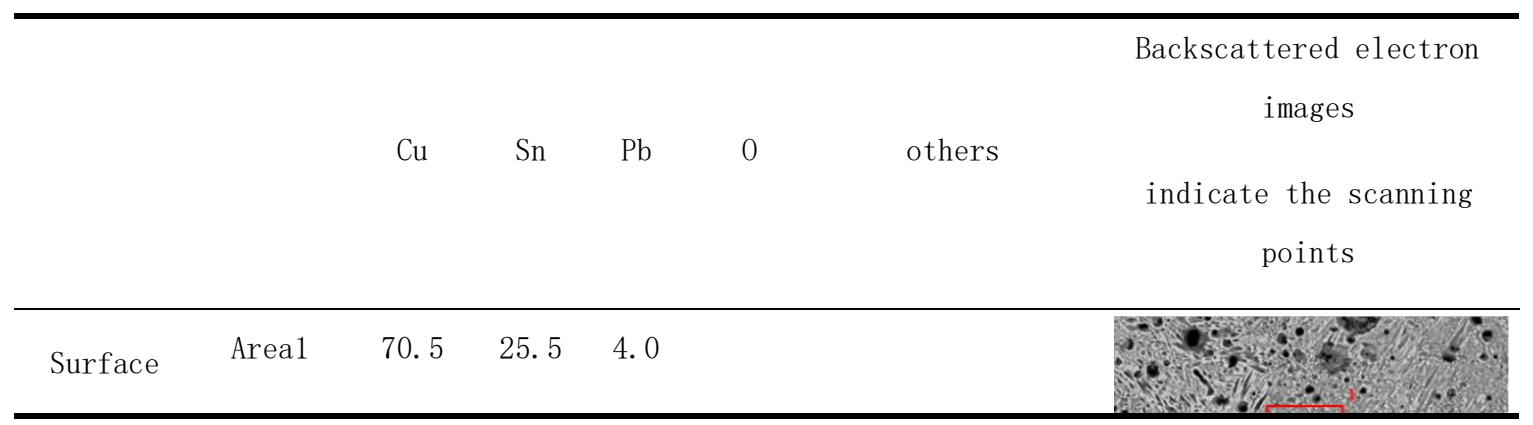




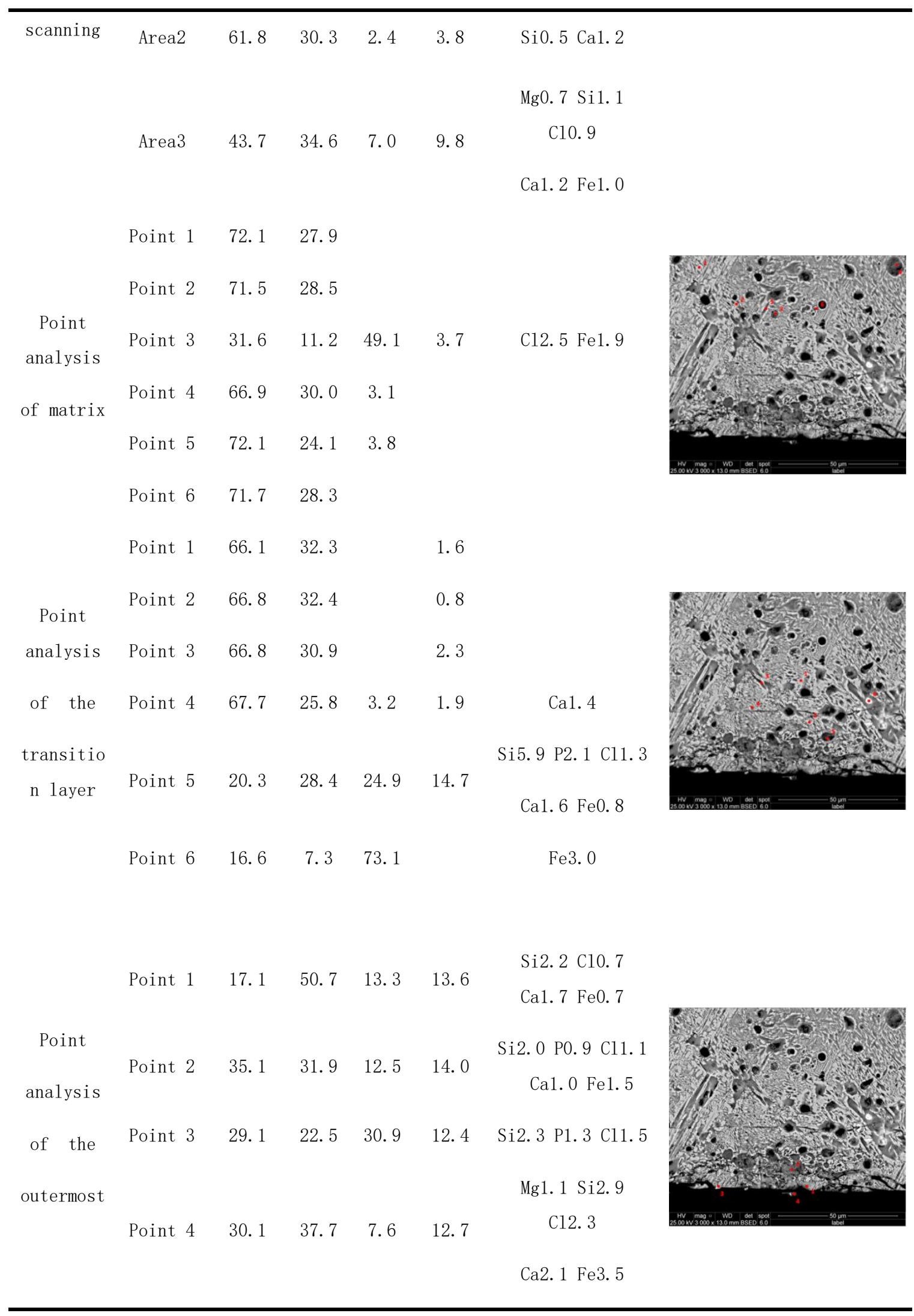

Table 2 EDS results for the sample with black lacquer 


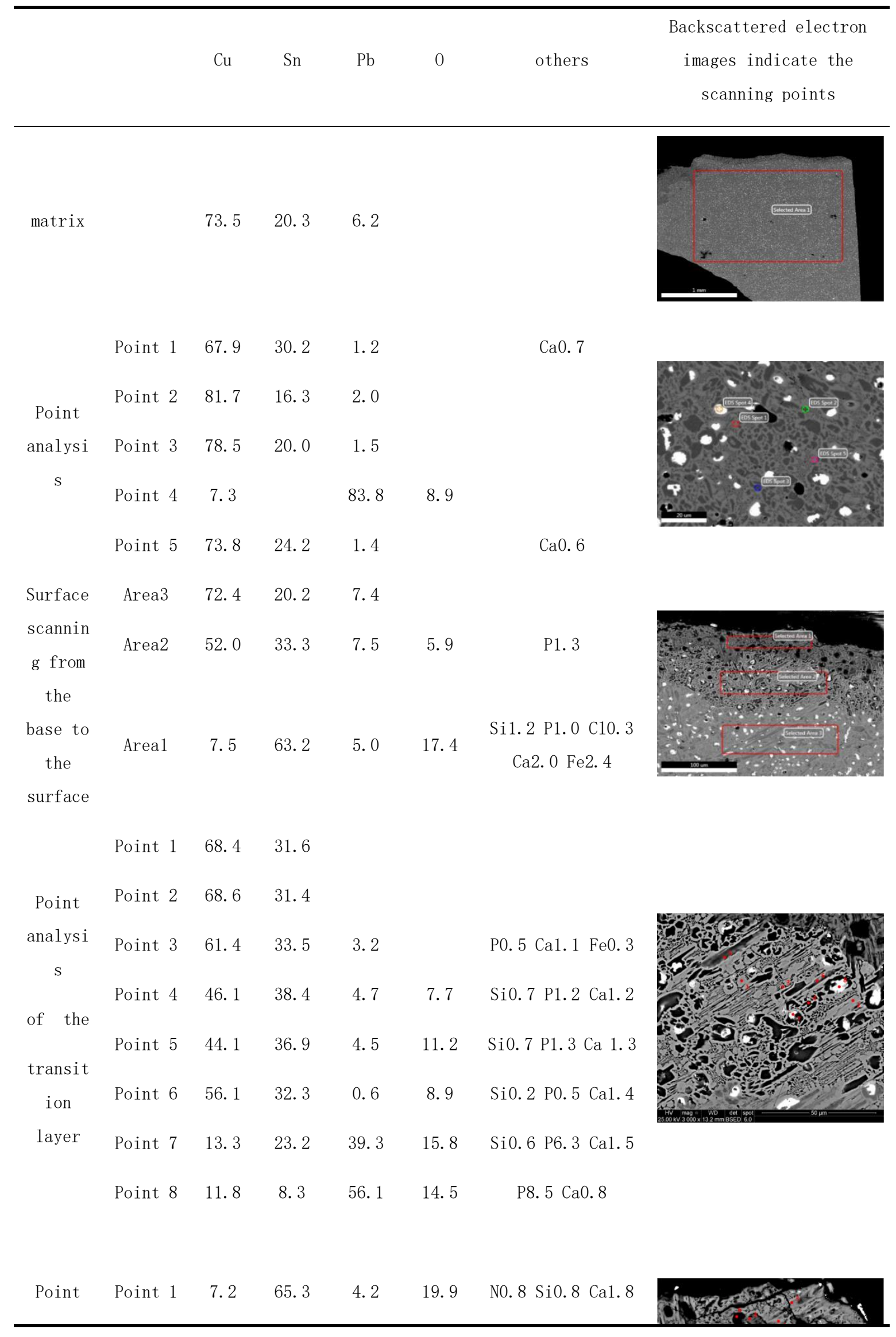




\begin{tabular}{|c|c|c|c|c|c|c|}
\hline analysi & Point 2 & 7.4 & 68.6 & 4.9 & 15.9 & N0. 6 Si0. 5 Ca2. 1 \\
\hline $\begin{array}{c}\text { S } \\
\text { of the }\end{array}$ & Point3 & 6.2 & 63.6 & 4.9 & 17.2 & $\begin{array}{c}\text { Si1. } 2 \text { P1. } 8 \text { Ca1. } 8 \\
\text { Fe3. } 3\end{array}$ \\
\hline $\begin{array}{c}\text { outermo } \\
\text { st }\end{array}$ & Point 4 & 6.1 & 58.4 & 5.7 & 18.2 & $\begin{array}{c}\text { Si1. } 6 \text { P2. } 3 \text { Ca2. } 1 \\
\text { Fe5. } 6\end{array}$ \\
\hline \multirow[t]{6}{*}{ layer } & Point 5 & 6.5 & 60.6 & 5.8 & 15. 7 & $\begin{array}{c}\text { Si1. } 3 \text { P2. } 2 \text { C10. } 4 \\
\text { Ca2. } 4 \text { Fe } 5.1\end{array}$ \\
\hline & Point 6 & 2.6 & 22.9 & 2.8 & 8.7 & $\begin{array}{c}\text { C60. } 9 \text { Si } 0.3 \text { Ca0. } 9 \\
\text { Fe0. } 9\end{array}$ \\
\hline & Point 7 & 7.4 & 66.5 & 4. 7 & 16.2 & Si1. 2 Ca2. 3 Fe 1.7 \\
\hline & Point 8 & 7.9 & 65.1 & 5.1 & 16. 7 & $\begin{array}{c}\text { N0. } 7 \text { Si0. } 8 \text { P0. } 8 \\
\text { Ca1. } 9 \text { Fe1. } 0\end{array}$ \\
\hline & Point 9 & 6.0 & 63.0 & 5.1 & 18.9 & $\begin{array}{c}\text { Si1. } 3 \text { P1. } 2 \text { Ca2. } 2 \\
\text { Fe2. } 3\end{array}$ \\
\hline & Point 10 & 8.1 & 66.5 & 5.0 & 16. 2 & $\begin{array}{c}\text { N1. } 2 \text { Si } 0.5 \text { Ca1. } 8 \\
\text { Fe0. } 7\end{array}$ \\
\hline
\end{tabular}

These two bronze mirrors are copper-tin alloy with lead. The tin content in the substrate of both mirrors all reach more than $20 \%$, which makes the copper mirror have higher hardness and brittleness [26] and be fit to be photographed. The presence of a small amount of lead improves the filling capacity of the bronze mirror and makes the decoration on the back of the mirror clear.

Tin-rich layer exists outside the two samples, and stratification can be seen. In the sample with silver lacquer, from inside to outside, the copper content decreased by $12 \%$ and $29 \%$ respectively, and the tin increased by $18 \%$ and $14 \%$ respectively. The amount of lead in the outermost layer is slightly higher. There are many impurity elements in the tin-rich layer which are not found in the matrix.

In the sample with black lacquer, from inside to outside, the copper content decreased by $28 \%$ and $85 \%$ respectively, and the tin increased by $64 \%$ and $89 \%$ respectively. The change range is obviously larger than the former. A small amount of nitrogen was detected at many points in the outermost layer. It was speculated that the structure of the outermost layer was loose and there were many cracks, which cause nitrogen fertilizer in the soil to seep into the surface.

According to the results of composition analysis, we named the two layers outside the matrix as nonmetal layer and transition layer respectively. The nonmetallic 
layer is composed of single $\mathrm{Sn}_{1-x} \mathrm{Cu}_{x} \mathrm{O}_{2}$ [27], and the transition layer is mainly composed of $\mathrm{Sn}_{1-x} \mathrm{Cu}_{x} \mathrm{O}_{2}$ and $\delta$ phase $\left(\mathrm{Cu}_{31} \mathrm{Sn}_{8}, 32.6 \% \mathrm{Sn}\right)$. Various impurity elements, such as silicon, aluminum, iron, etc, which are not found in the matrix alloy, are found in the ancient lacquer layer.

1. Formation mechanism of tin-rich layer for the mirror with" black lacquer" Some scholars analyzed the sample of a mirror with black lacquer in Han Dynasty by means of metallographic microscope and scanning electron microscope, and confirmed that there is a "trace image" of the original metal structure on the outermost layer, which indicates that the tin-rich layer on the surface of the "black lacquer" bronze mirror is not an external additional deposition layer[19]. Simulation experiment using humic acid solution to soak bronze mirror to simulate the corrosion process of mirror in soil proved that the humic acid treatment of mirror could produce tin oxide on its surface[18].

According to the electrochemical principle, the $\delta$ phase in bronze alloy is most easily corroded [28-30], but in this analysis of the black lacquer, the a phase is corroded first. The reason has been revealed: in the transition layer of black lacquer, there is a kind of overlapping position lattice structure between $\delta$ phase and $\mathrm{SnO}_{2}$. This structure greatly reduces the energy of copper atoms at the interface and effectively protects the $\delta$ phase from corrosion [19].

Combine with previous research, the black lacquer surface should have been formed by natural corrosion.

From inside to outside, the copper content decreases and the tin content increases greatly.

The high tin content in the substrate and the action of humic acid in the soil environment are the factors that lead to the formation of black lacquer on the surface of mirror. The presence of more impurity elements in the surface layer was also the result of soil action.

2. Formation mechanism of tin-rich layer for the mirror with" silver lacquer"

In the natural corrosion of the black lacquer, from inside to outside, the copper decrease the and tin content increase greatly. However, the content of tin in the transition layer and the outermost layer of the silver lacquer is close and the loss of copper is not very large. The silver lacquer surface is relatively dense and corrosion degree is far less than black lacquer mirror.

The interconnections and cracks between the transition layer and the matrix were 
observed in the black lacquer, which does not exist in the silver lacquer. Therefore, silver lacquer was not formed by natural corrosion but human treatment.

Tangkun He et al. [7, 31,32] believed that the surface of bronze mirror was treated with tin amalgam in ancient China. Qinglin Ma et al. [33] conducted a simulation experiment, showing the structure of tin-rich layer obtained by amalgam and hot tinning is similar.

Compared with gold mercury compounds, tin mercury compounds have lower decomposition temperature, and exist in the form of $\mathrm{Sn}_{7-9} \mathrm{Hg}$. After a long time, mercury will decompose and release completely, so it is highly unlikely that mercury will be detected[34]. Therefore, the existence of tin amalgam method cannot be judged by the presence or absence of mercury.

Scholars in Shanghai Museum [35] have done a lot of work and believe that the "silver lacquer" of bronze mirror is obtained by rubbing grinding powder repeatedly on the mirror surface. Grinding powder is made by mixing tin, mercury, calcium, potassium, sulfur, aluminum and other auxiliary materials. Potassium and aluminum were not detected in the analysis of this paper.

A new explanation has been proposed for the tin-rich surface mirror $[11,12]$. The tin-rich copper-mixed amalgam is deposited on the surface of the electroplated object by hot plating, resulting in metallurgical chemical reaction rather than mechanical adhesion. Any method using amalgam requires a process of heating to remove mercury. Finally, the surface layer including $\eta, \varepsilon, \delta$ is obtained, and each phase is arranged hierarchically. Because the process is too complex and the control of experimental conditions is relatively difficult, it is less possible to treat the surface of copper mirror with this method.

In the above study, the phenomenon of lead enrichment is found at the junction between the surface layer and the substrate of mirror with silver lacquer (Fig. 9). The lead content in the matrix is only about $4 \%$, which is not high. The metallographic structure of the matrix also reflects the uniform distribution of lead particles. The size of the mirror itself is small, and the bronze alloy solidified quickly during casting, which is not enough to cause lead segregation and subsidence. It is clear that the lead at the interface is clearly external. Therefore, we hypothesized that lead-tin amalgam was used instead of tin amalgam. 


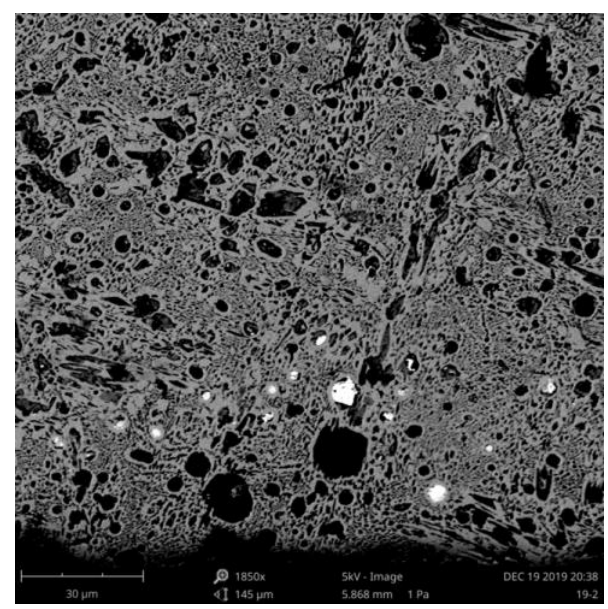

Fig. 9 Lead enrichment between substrate and surface layer

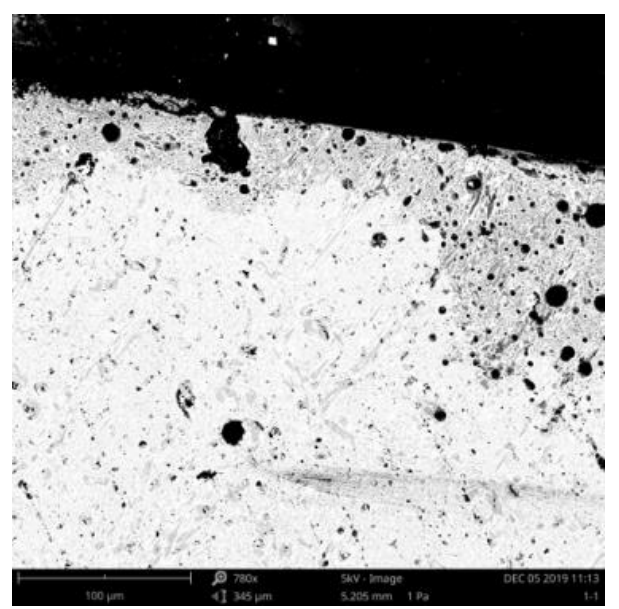

Fig. 10 the arrangement of shrinkage cavities along the interface

Elemental tin was originally smelted from oxidized ore, but it was smelted from sulfide ore in the Han Dynasty. The tin obtained was not pure and generally contained a small amount of lead.

The diffusion coefficients of lead and tin in mercury are similar [36]. Coating with lead-tin amalgam on the surface of the mirror. The mercury in the amalgam, as a temporary adhesive, making the amalgam and the matrix adhered, which is mechanically engaged with the matrix.

Heating to drive mercury is a process of mutual diffusion and fusion between copper in the matrix and tin in the coating in which lead does not participate. The lead in the coating is gradually deposited between the substrate and the surface layer. At the same time, the arrangement and aggregation of shrinkage cavities along the interface trend are observed (Fig. 10), and it is speculated that the defects should be caused by mercury evaporation and escape [37]. It maybe these defects that cause the coating to be not closely combined with the substrate, and then some copper rust appeared on the surface with silver lacquer. 


\section{Conclusions}

Two mirrors are copper-tin alloy with lead, and the matrix structure is in as-cast state without any trace of heating homogenization. It has the same composition and organization as the typical bronze mirror of Han Dynasty in ancient China.

There are transition layer and non-metallic layer outside the substrate of two copper mirrors. From the inside to the outside, the copper content decreased gradually, and the tin content increased gradually, but the change range is obviously different, among which the change range of the black lacquer is much more obvious. Some impurity elements which are not found in the matrix appear in the tin rich layer.

The surface layer of both mirrors is rich in tin, but the formation mechanism is different.

It is speculated that the surface of "black lacquer" mirror was natural corrosion, which is produced together by the high tin content of the matrix and environmental humic acid.

The surface of "silver lacquer" was treated with lead-tin amalgam. which include two processes: mechanical bonding and micrometallurgy. Lead reduces the reaction temperature, expands the melting point range, and promotes the metallurgical combination.

Mercury is first used as a medium to bond the amalgam coating to the substrate. The mercury is then heated to escape, but the temperature is not so high that there is no evidence of heating homogenization in the matrix.

The mercury escapes too completely to be detected by being heated and buried for years.

\section{Abbreviation}

SEM - EDS: scanning electron microscope energy - dispersive spectrometry.

\section{Acknowledgements}

We are thankful to Doctor Zheng 1onglong from School of History, Zhengzhou University and Feng Zhang from Henan Provincial Institute of Cultural Heritage and Archaeology for providing the samples. The technical support from Henan Provincial Institute of Cultural Heritage and Archaeology is greatly appreciated.

\section{Authors' contributions}


ZY analyzed and interpreted the patient data. JZ performed the examination and was a major contributor in writing the manuscript. XW provides great convenience for sample acquisition and analysis. All authors read and approved the final manuscript.

\section{Funding}

There is no funding supported for this research.

\section{Availability of data and materials}

All data generated or analyzed during this study are included in this article.

\section{Competing interests}

The authors declare that they have no competing interests.

\section{Author details}

${ }^{1}$ School of History, Zhengzhou University, 100 Science Road, Zhengzhou 450000, People' s Republic of China. 'Henan Provincial Institute of Cultural Heritage and Archaeology, Zhengzhou 450000, Henan Province, China.

\section{References}

1. Zhao $\mathrm{XH}$ (Song Dynasty).Dongtian Qinglu collection;Integration of ancient and modern books $\cdot$ Economic Compilation $\cdot$ Kaogong Dian • Mirror section.Photocopies of Zhonghua Book Company.Volume 698.p.225-227.

2. O. Karlbeck. Notes on Some Early Chinese Bronze Mirrors. The China Journal of Scienceand Arts .1926;4(1): 4.

3. W. P. Yetts. Problems of Chinese Bronzes.Journal of the Royal Central Asian Society.1931;18: 399-402.

4. W. F. Collins. The Mirror-black and "Quicksilver" Patinas of Certain Chinese Bronzes. Journal of the Royal Anthropological Institute , LXIV.1934;69-79.

5. R. J. Gettens. Some Observations Concerning the Lustrous Surface on Ancient Eastern Bronze Mirrors. Technical Studies in the Field of Fine Arts.1934;3: 29-67.)

6. He TK,Song YQ.Surface analysis of bronze mirror in Linyi, China.Sichuan cultural relics. 1994;06

7. Lian HP. Research on surface treatment technology of "silver lacquer" bronze mirror in Eastern Han Dynasty.China Cultural Heritage.2004;03:44

8. Tan DR,Wu LM,Tang JJ,Su LM.Study on mechanism of surface formation of ancient "silver lacquer" bronze mirror.Sciences of Conservation and Archaeology.1997;01:1-9.

9. Wu LM.Study on surface treatment experiment of bronze mirror and related problems.Journal of Shanghai Museum.2000;00:698-706.

10. Wu YK,Chu RB.Exploration on the plating and welding technology of rich-tin copper on the surface of ancient Chinese bronzes. The first part-Application of rich-tin copper plating in ancient bronzes. Electroplating and Finishing.2012;06:46-49. The second part-The principle and process design of gilding.Electroplating and Finishing.2012;07:50-54.The third part — Welding.Electroplating and 
Finishing.2012;08:53-56

11. Wen JB,Wu YK.A preliminary Study on the history of metal plating technology in ancient China and its technical theory. Electroplating and Finishing.2016;12:651-658.

12. Yin $\mathrm{Z}, \mathrm{Xu} \mathrm{WK}, \mathrm{Zhang} \mathrm{JC}$.Discussion on controversial issues in bronze mirrors based on ancient bronze mirror manufacturing technology.China Cultural Relics News.2015; Version 7.

13. W. T. Chase. What is the smooth lustrous black surface on ancient bronze mirrors? Corrosion and metal artefacts, a dialogue between conservators, archaeologists and corrosion scientists. Washington: National Bureau of Standards Special Publication. 1977; 479: 191-203.

14. W. T. Chase, U. M. Franklin. Early Chinese black mirrors and pattern-etched weapons.Ars Orientalis. 1979;(11): 215-258.

15. Li SZ.Test and research on the surface composition of ancient Chinese bronze mirrors and bronze swords.Journal of Chengdu University of Science and Technology.1984;03:153-158+152.

16. R. J. Gettens. Tin-oxide patina of ancient high-tin bronze. Bulletin of the Fogg Art Museum.1949,;11 (1): 16-26.

17. W. F. Collins. The mirror-black and "Quicksilver" patinas of certain Chinese bronzes. Journal of the Royal Anthropological Institute,LXIV.1934;69-79.

18. Sun SY,Ma ZZ,Jin LJ,et al.The effect of humic acid in soil on the formation of black lacquer on the surface of bronze mirror.Cultural relics.1992;12:79-89.

19. Sun SY,Zhou ZF,Li QM,et al.Research on the "Marks" in "Black lacquer" on the surface of the bronze mirror-The second study on the formation mechanism of "Black lacquer".Studies of the history of natural science.1996;15(2).

20. Ma ZZ,Jin LJ,Yin XL.Study on the formation of black lacquer on the surface of tin bronze mirror by humic acid.Archeology.1994;3.

21. Ma ZZ.Research progress of “black lacquer” bronze mirror.College Chemistry.1995;10(2).

22. Ma ZZ,Du L,Fang CY.The structure of the black lacquered surface of the bronze mirror.Journal of Mineral Metallurgy and Materials (English Edition).1996;2.

23. Zhou ZF.The formation mechanism of "lacquer" layer in high tin bronzes.Doctoral dissertation of University of Science and Technology Beijing;1998.

24. He TK.Analysis and research on Several dark surfaces of ancient bronze mirrors.Journal of Archaeology.1987;1:119-131.

25. Chen YY,Huang YL,Yang YN,Chen H.Experimental research on simulating "Black lacquer" bronze mirrors.Archeology.1987;02:175-178+199-200.

26. Sun SY,N.F.Kennon.Study on the microstructure of ancient Bronze mirrors in China.Studies of the history of natural science. 1992;01:54-67+97-98.

27. Wu YS,Wang CS,Fan CZ.Discussion on corrosion resistance mechanism of "Ancient black lacquer".Journal of physics.1992;41(1):170-176.

28. Wang CS,Fan CZ,Wang SJ,Zhang MS,Zhang JG,W.T.Chase.Study on the Powdery Rust of Caihou Chimes.Science in China(Part B Chemistry, life science, Geoscience).1990;06:639.

29. Chen XJ,Huang HJ,et al.Basic Course of Metal Corrosion and Protection.Beijing:Machinery Industry Press.1988. 
30. Fan CZ,Wang CS,Wang SJ,Zhang MS,Zhang JG,W.T.Chase,Han ZQ.Study on the formation mechanism of powdery rust on bronze.Science in China(Part B Chemistry, life science, Geoscience).1991;03:239.

31. He TK.Surface analysis of Bronze Mirror in Echeng,China.Studies of the history of natural science.1987;02:175-187+194

32. He TK.Scientific analysis of several bronzes in the Dian Lake Area,China.Cultural Relics.1985;04:59-64.

33. Ma QL,David A. Scott..Tinned bronze belt plaques during Spring-Autumn period in Northwest China: A technique study.Scientific and Technological Research of Cultural Relics.2007;5:24-40.

34. Wu YK,Chu RB.Exploration on the plating and welding technology of rich-tin copper on the surface of ancient Chinese bronzes. The first part-Application of rich-tin copper plating in ancient bronzes.Electroplating and Finishing.2012;06:46-49. The second part-The principle and process design of gilding.Electroplating and Finishing.2012;07:50-54.The third part - Welding.Electroplating and Finishing.2012;08:53-56

35. Tan DR,Wu LM,Tang JJ,Su LM.Study on mechanism of surface formation of ancient "silver lacquer" bronze mirror.Sciences of Conservation and Archaeology.1997;01:1-9.

36. Zhang CG.Diffusion coefficient and diffusion law of metals in mercury.Chemical Bulletin.1980;12:6-13.

37. Shen CY,Li J.Preparation of Uranium protective coating by Amalgamation method.Rare Metal Materials and Engineering.2013;2:377-381. 
Figures

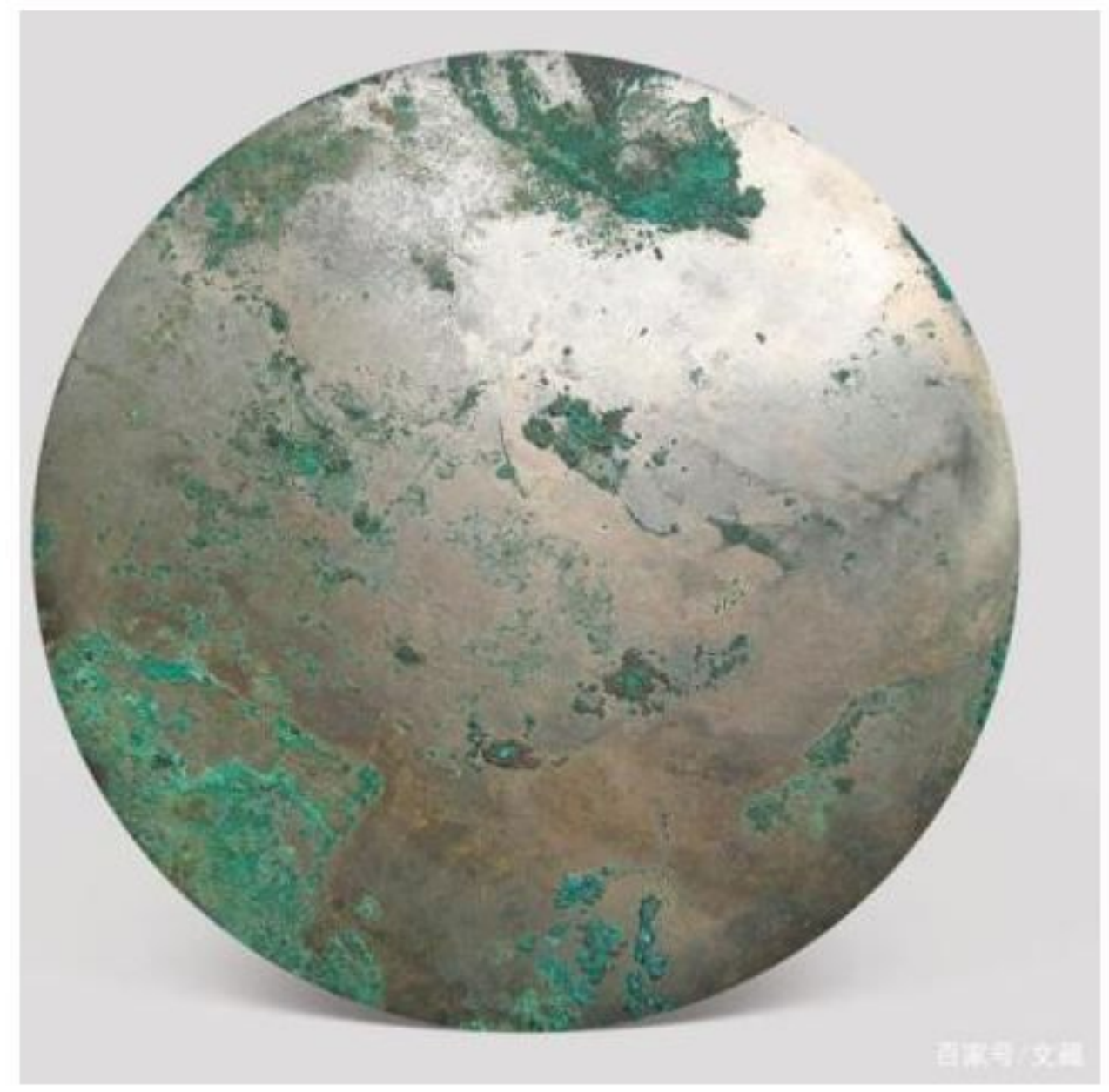

Figure 1

silver lacquer"mirror 


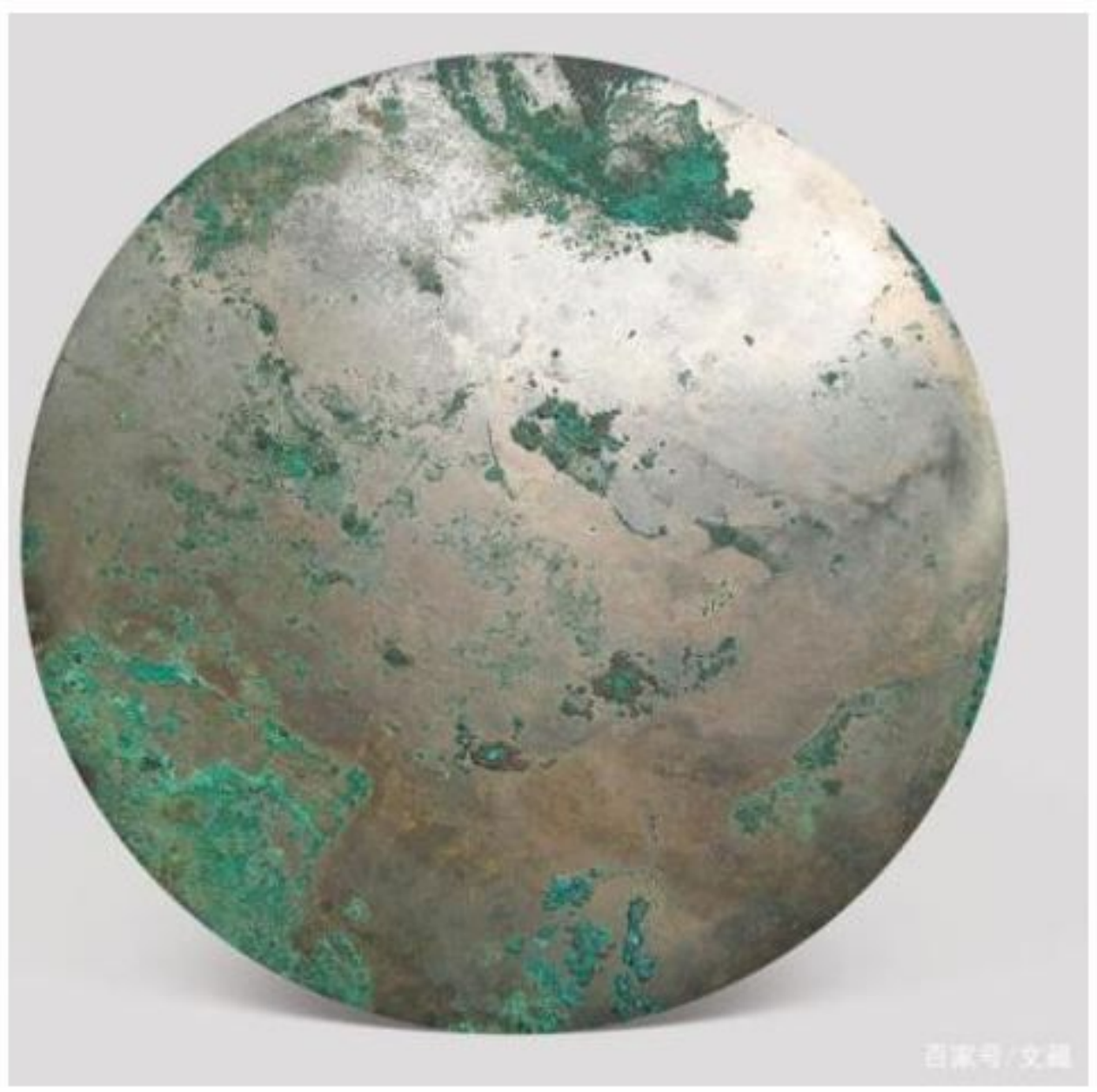

Figure 1

silver lacquer"mirror 


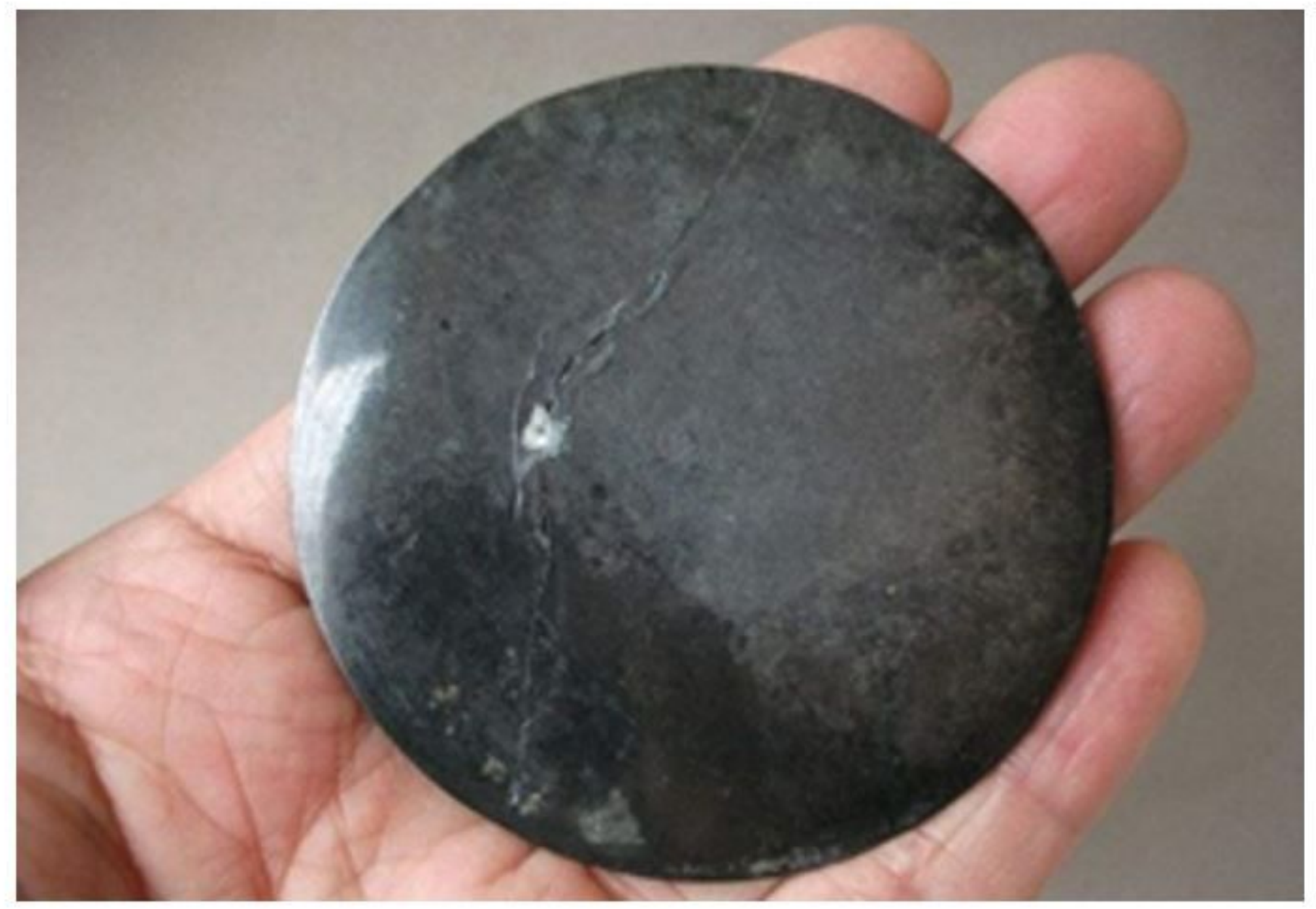

Figure 2

Black lacquer" mirror 


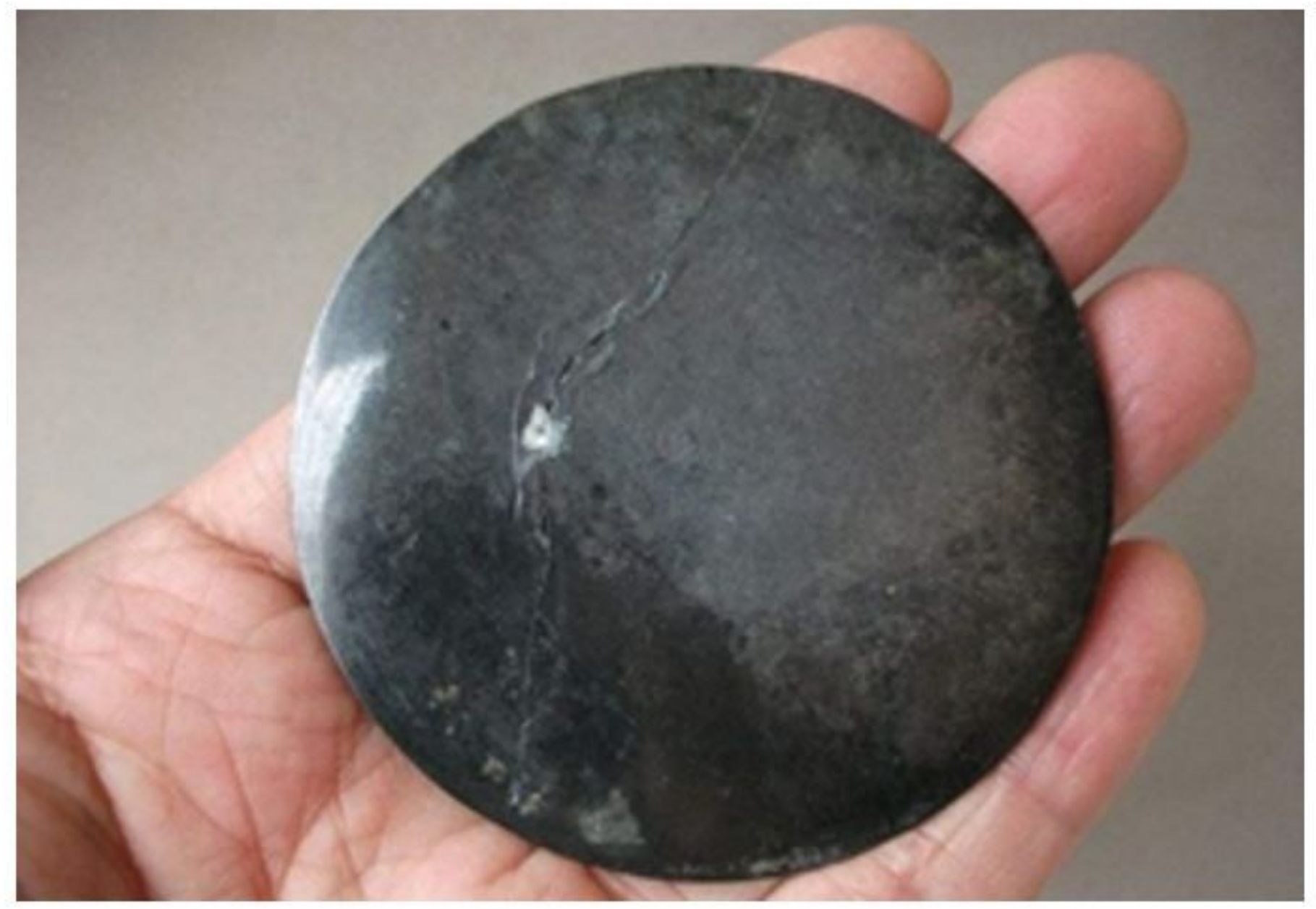

Figure 2

Black lacquer" mirror 

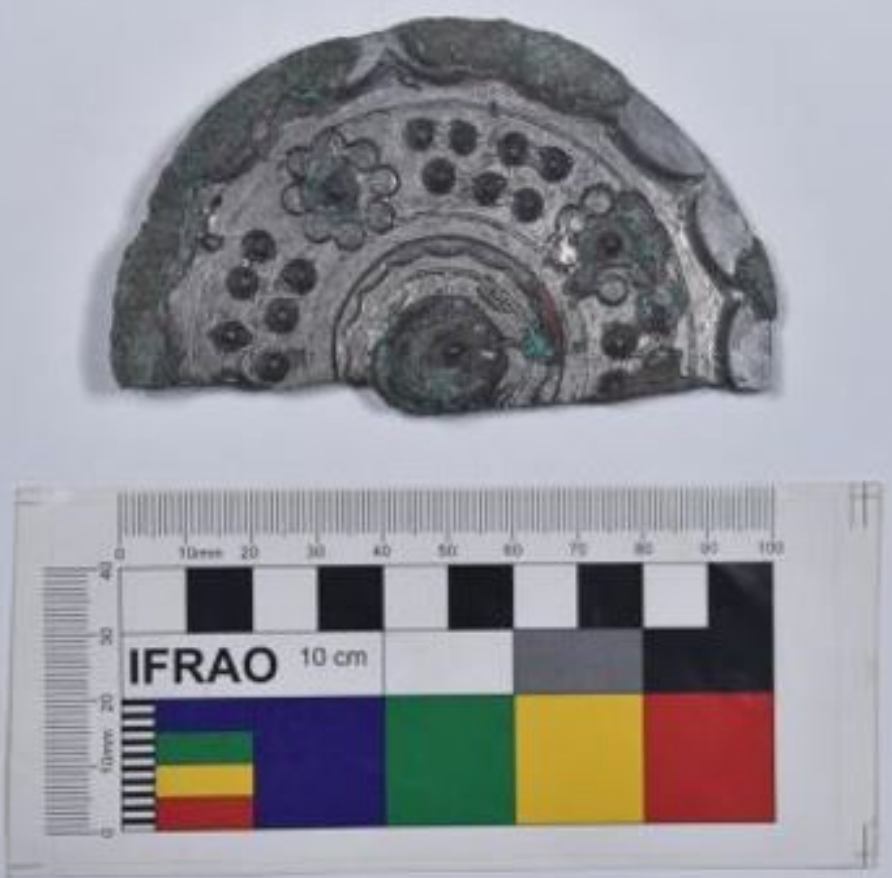

\section{Figure 3}

silver lacquer"mirror

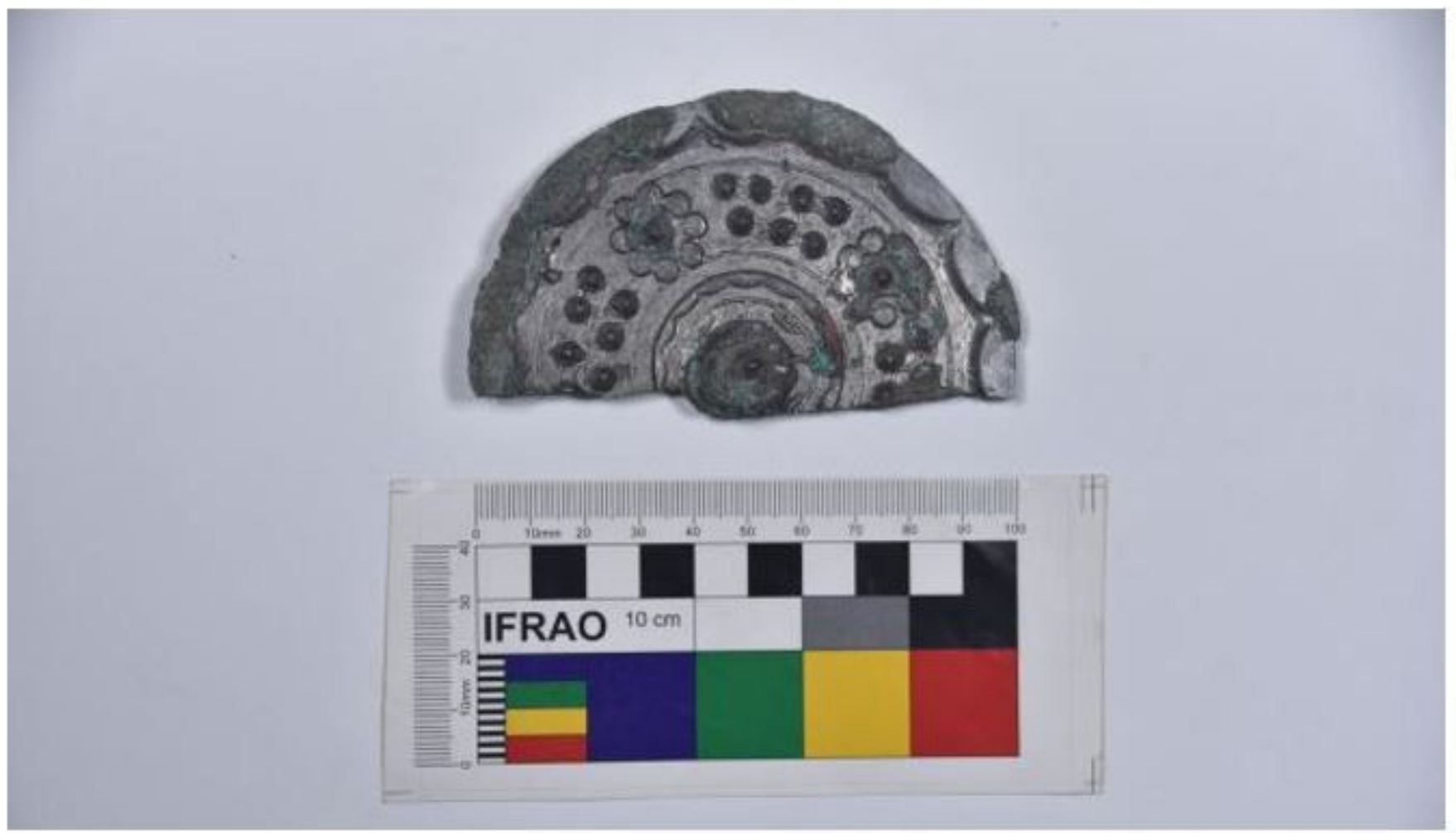

Figure 3 
silver lacquer"mirror

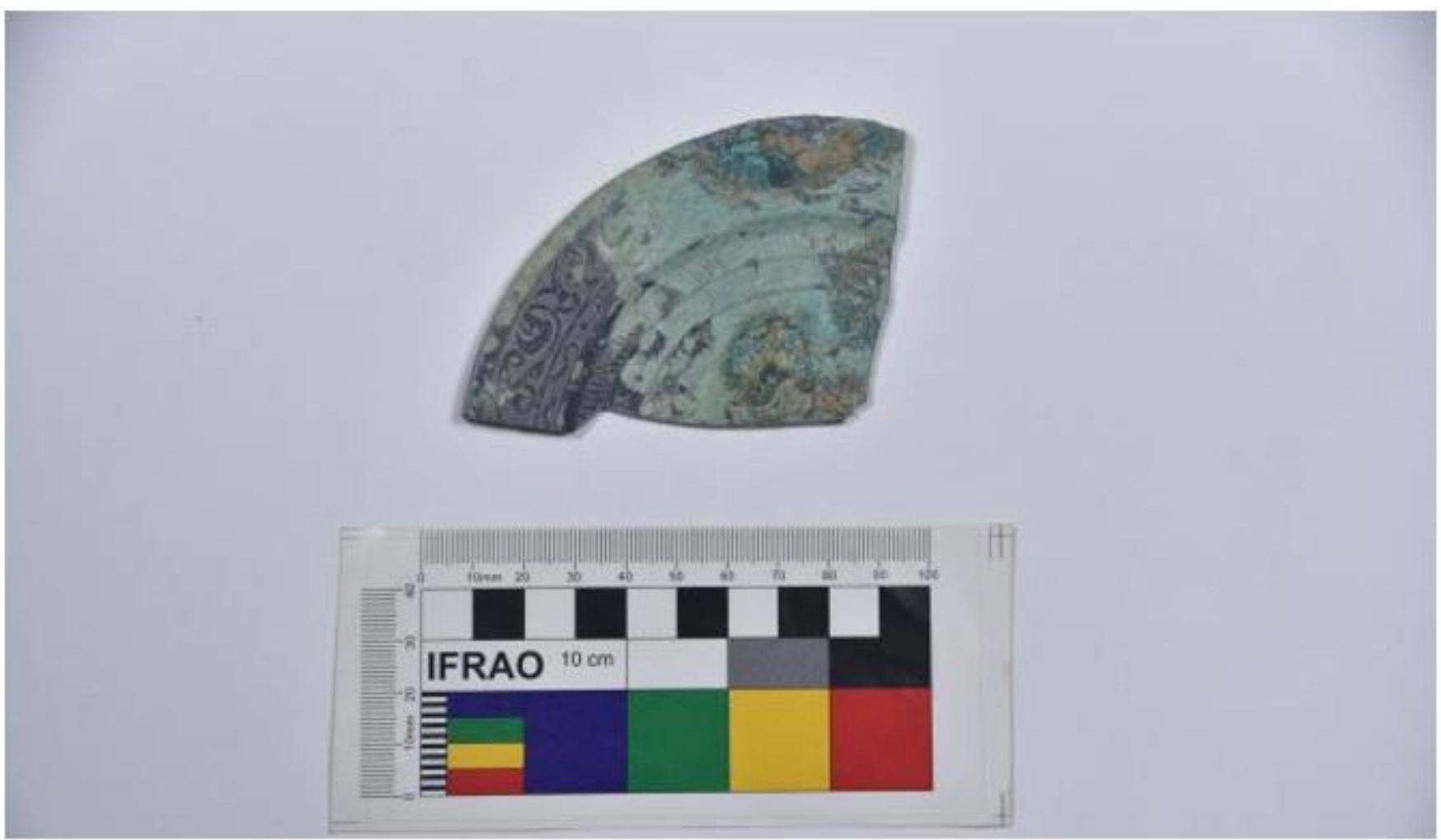

Figure 4

Black lacquer" mirror
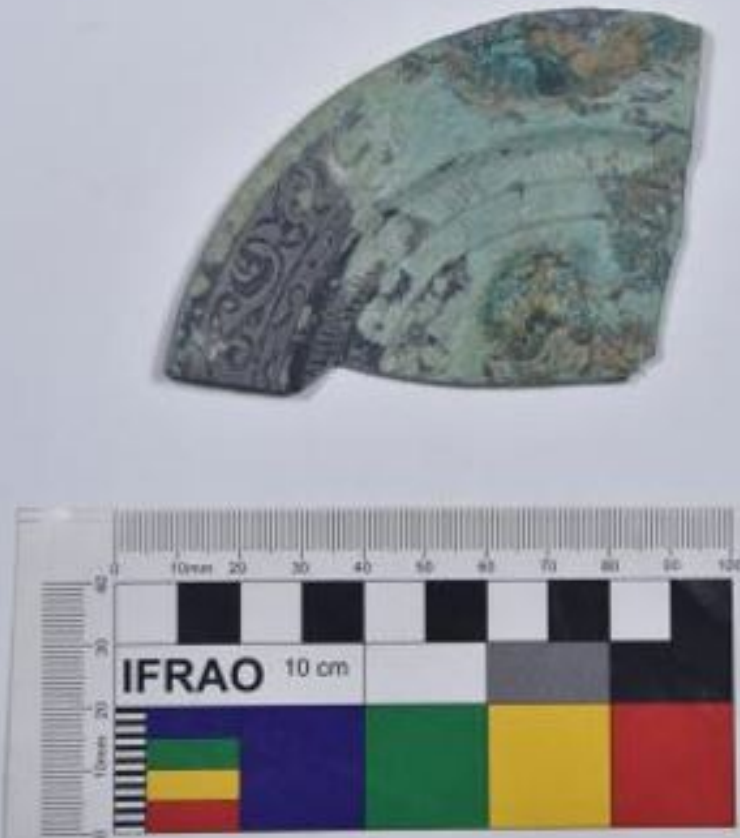


\section{Figure 4}

Black lacquer" mirror
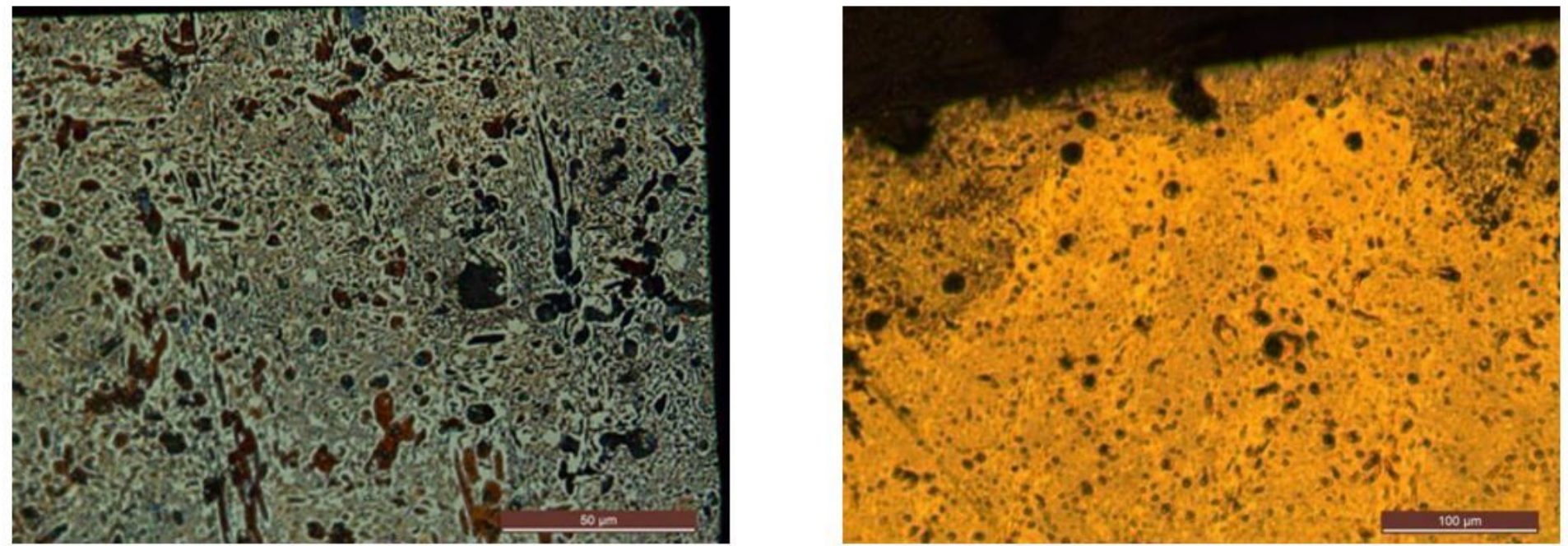

\section{Figure 5}

metallograph (left: matrix; right: matrix and the surface layers)
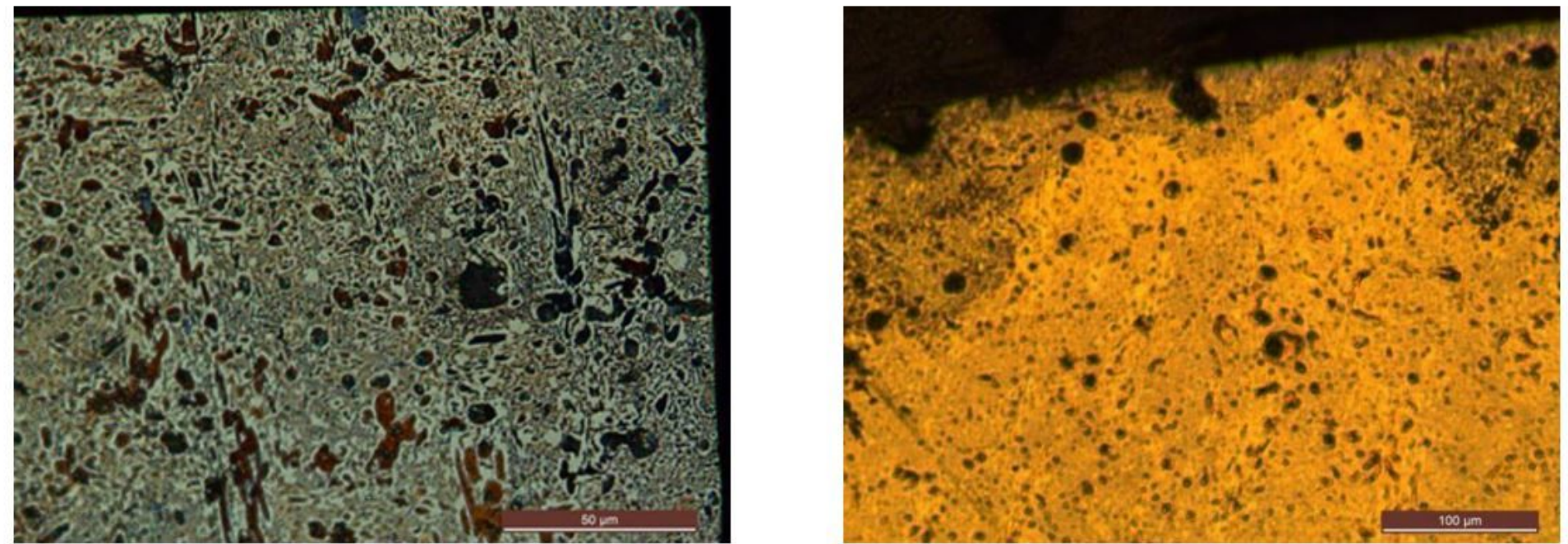

Figure 5

metallograph (left: matrix; right: matrix and the surface layers) 

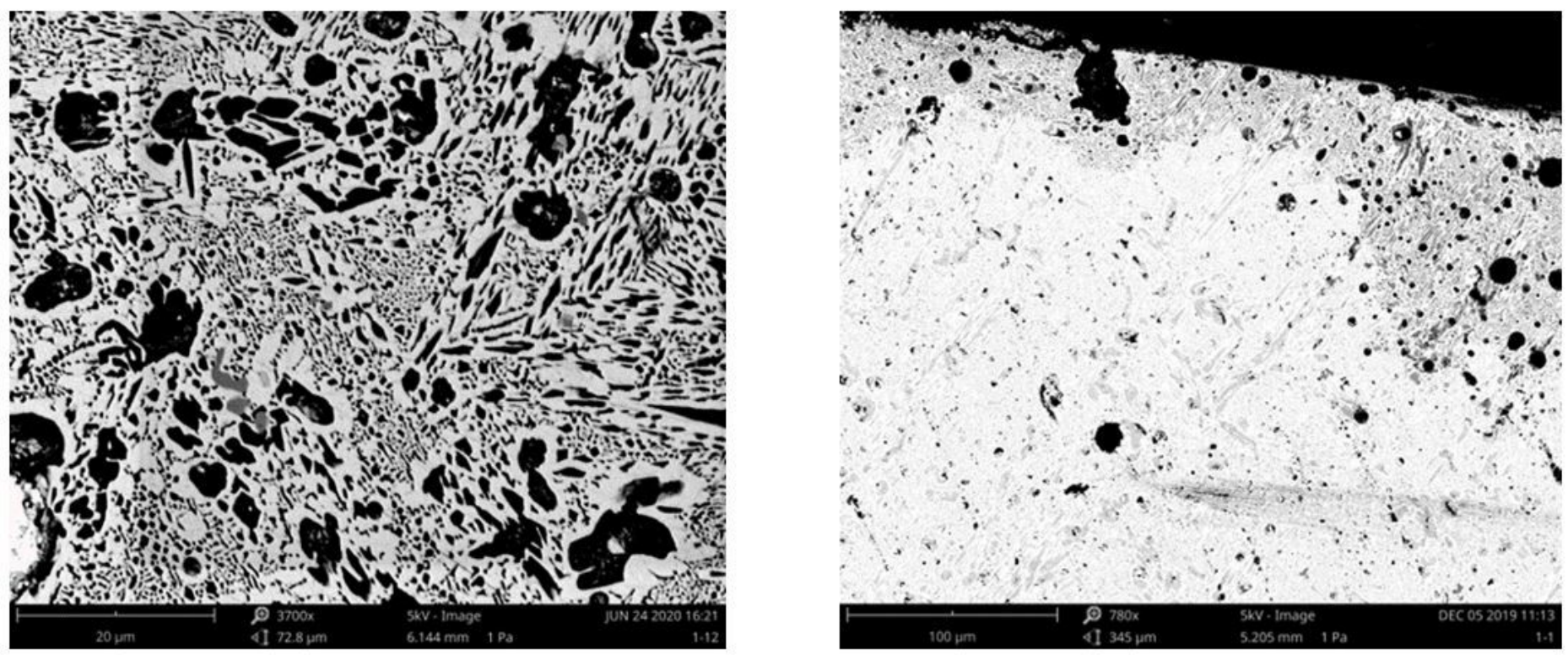

Figure 6

backscattered electron imaging(left: matrix; right: matrix and surface layers)
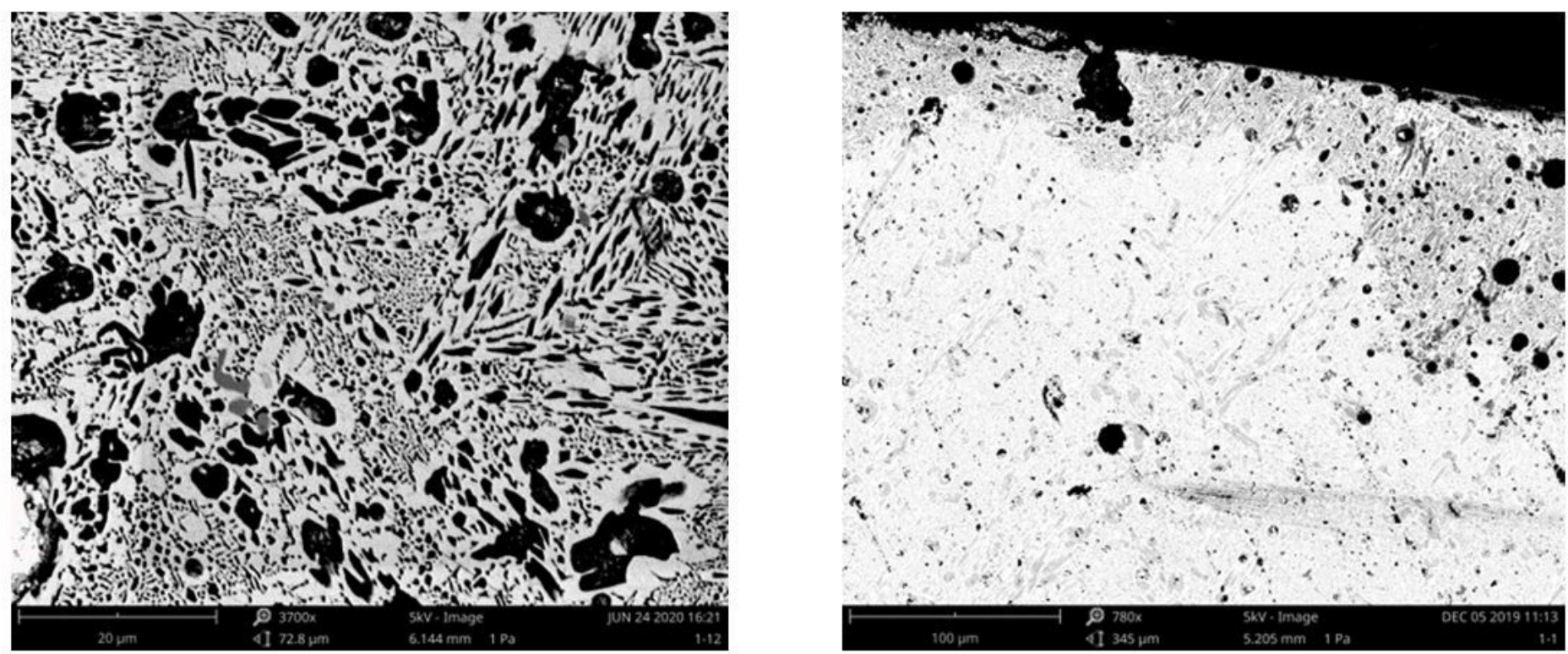

Figure 6

backscattered electron imaging(left: matrix; right: matrix and surface layers) 

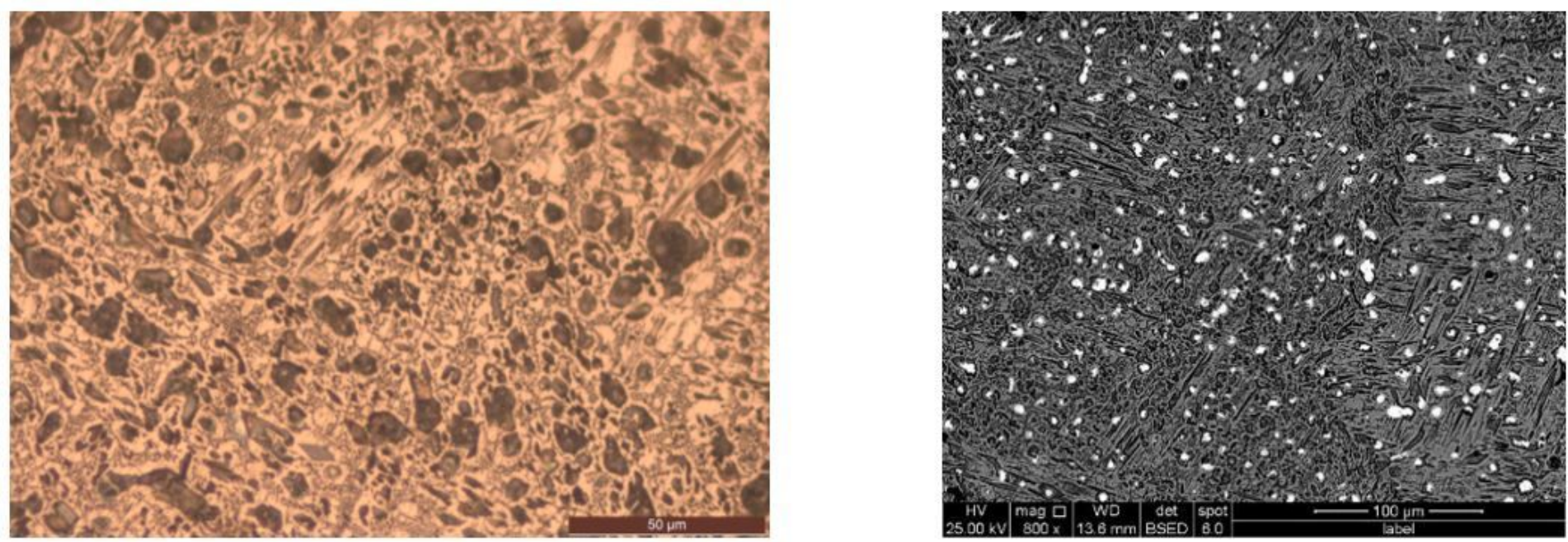

\section{Figure 7}

the matrix (left:metallographic; right:backscattered electron imaging )
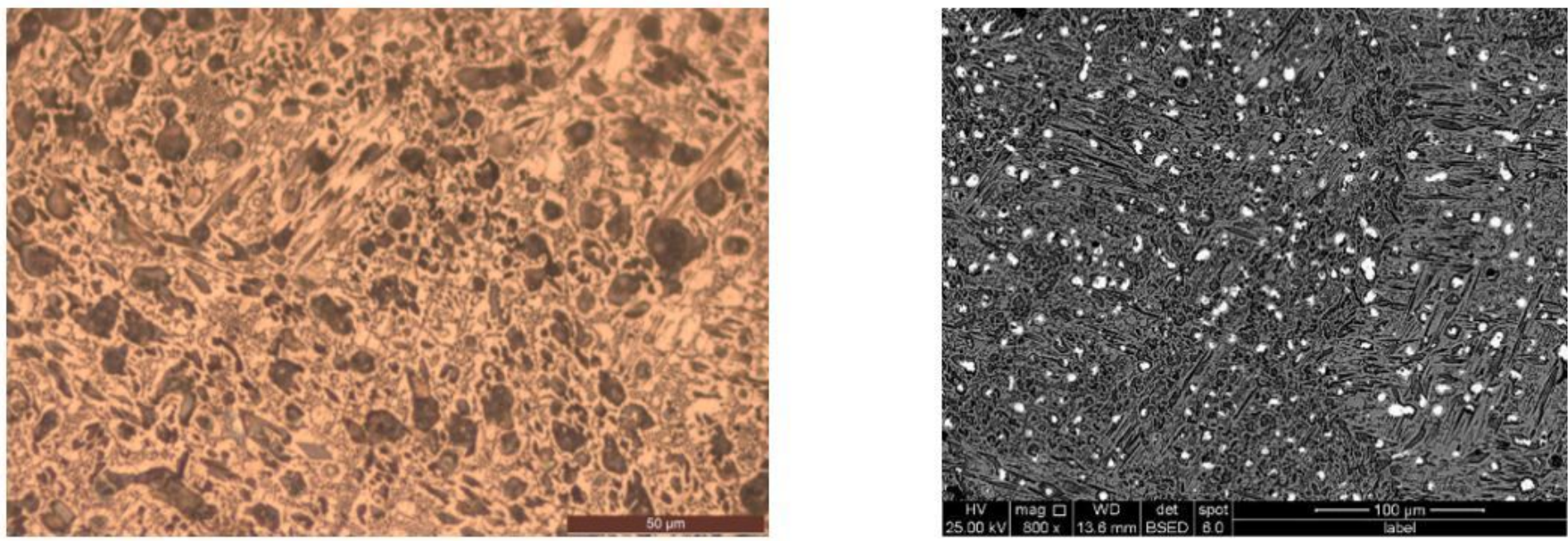

\section{Figure 7}

the matrix (left:metallographic; right:backscattered electron imaging ) 

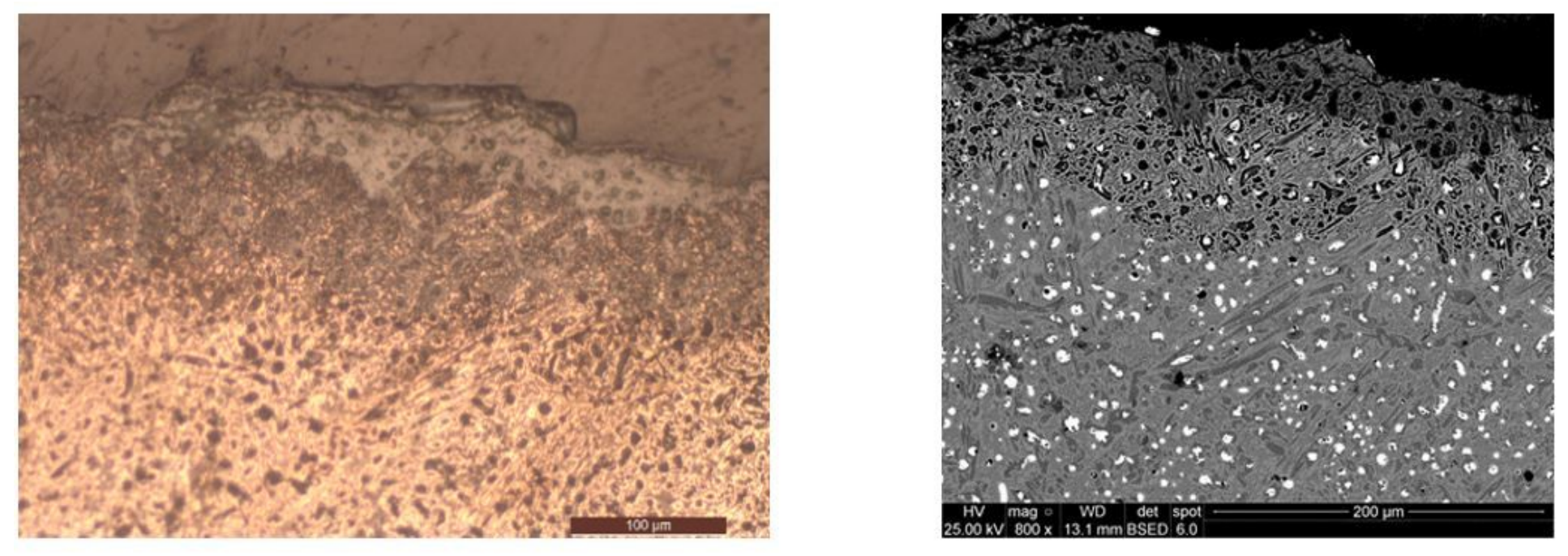

\section{Figure 8}

the matrix and surface layers (left:metallographic ; right: backscattered electron imaging )
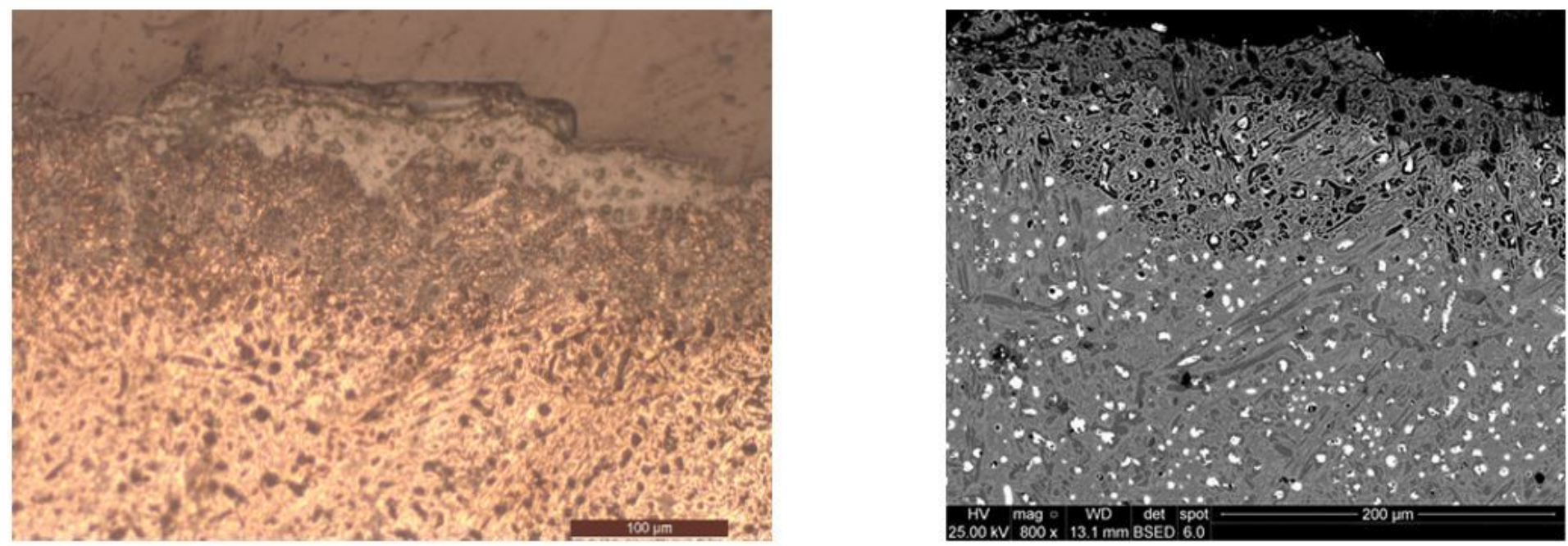

\section{Figure 8}

the matrix and surface layers (left:metallographic ; right: backscattered electron imaging ) 


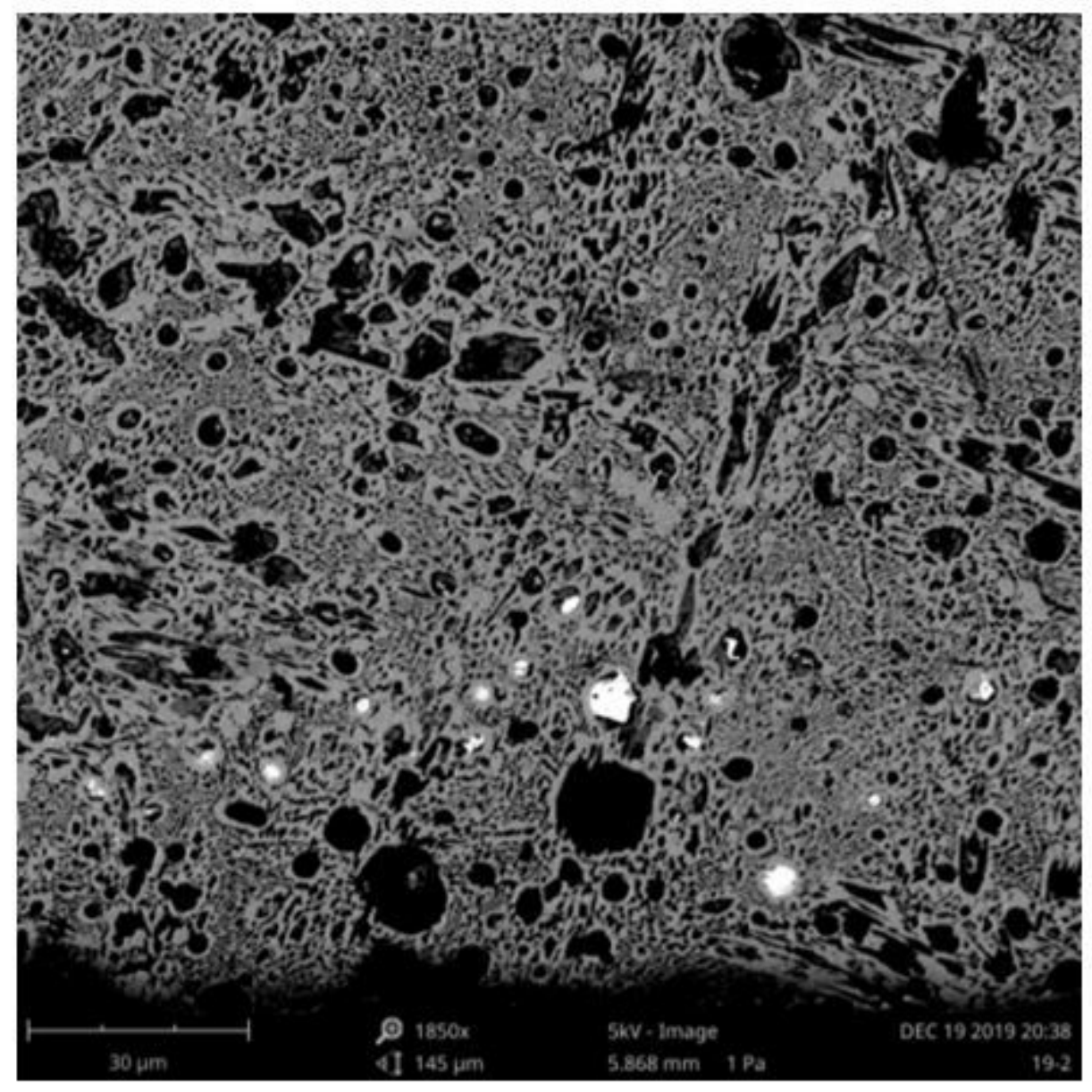

Figure 9

Lead enrichment between substrate and surface layer 


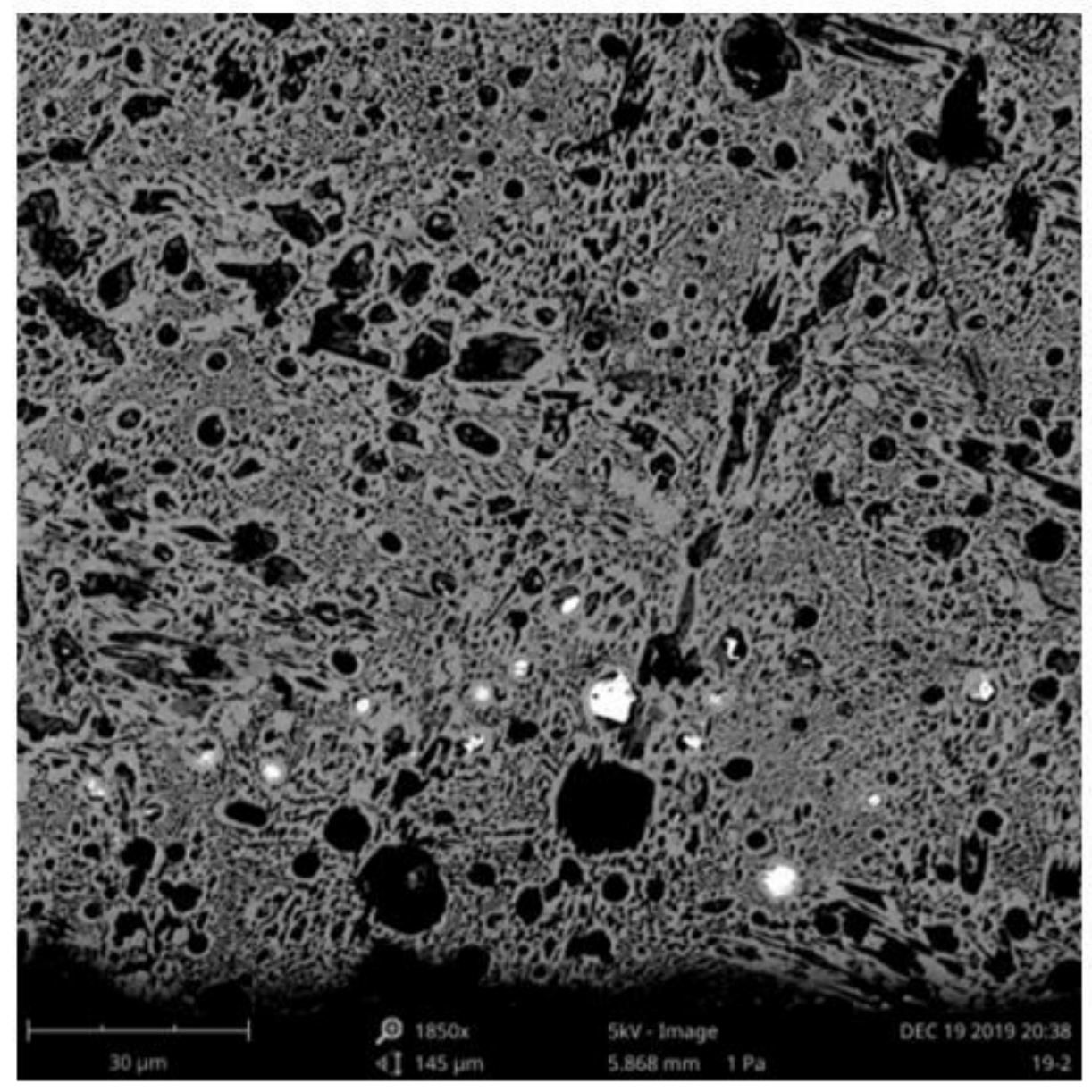

Figure 9

Lead enrichment between substrate and surface layer 


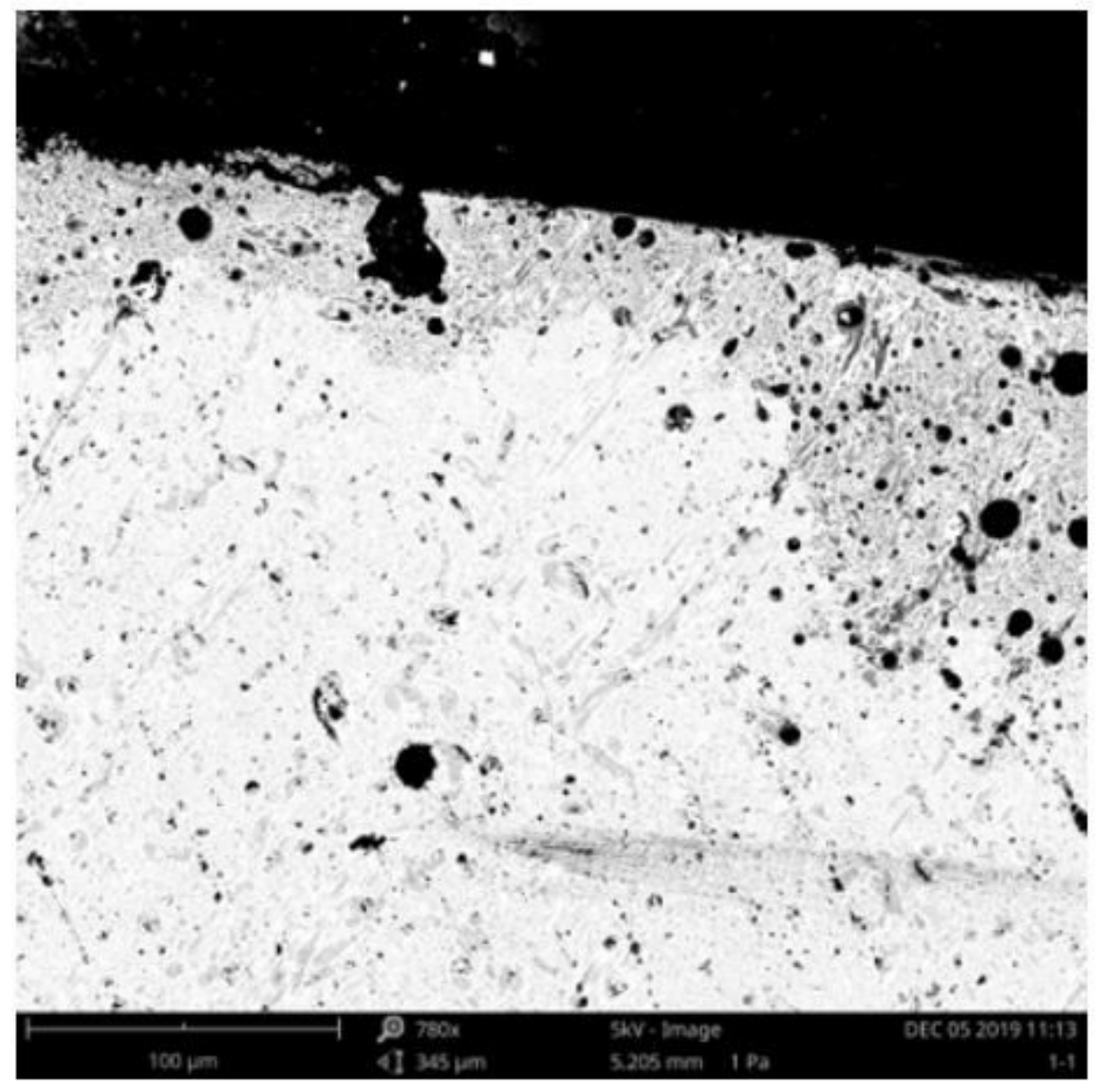

Figure 10

the arrangement of shrinkage cavities along the interface 


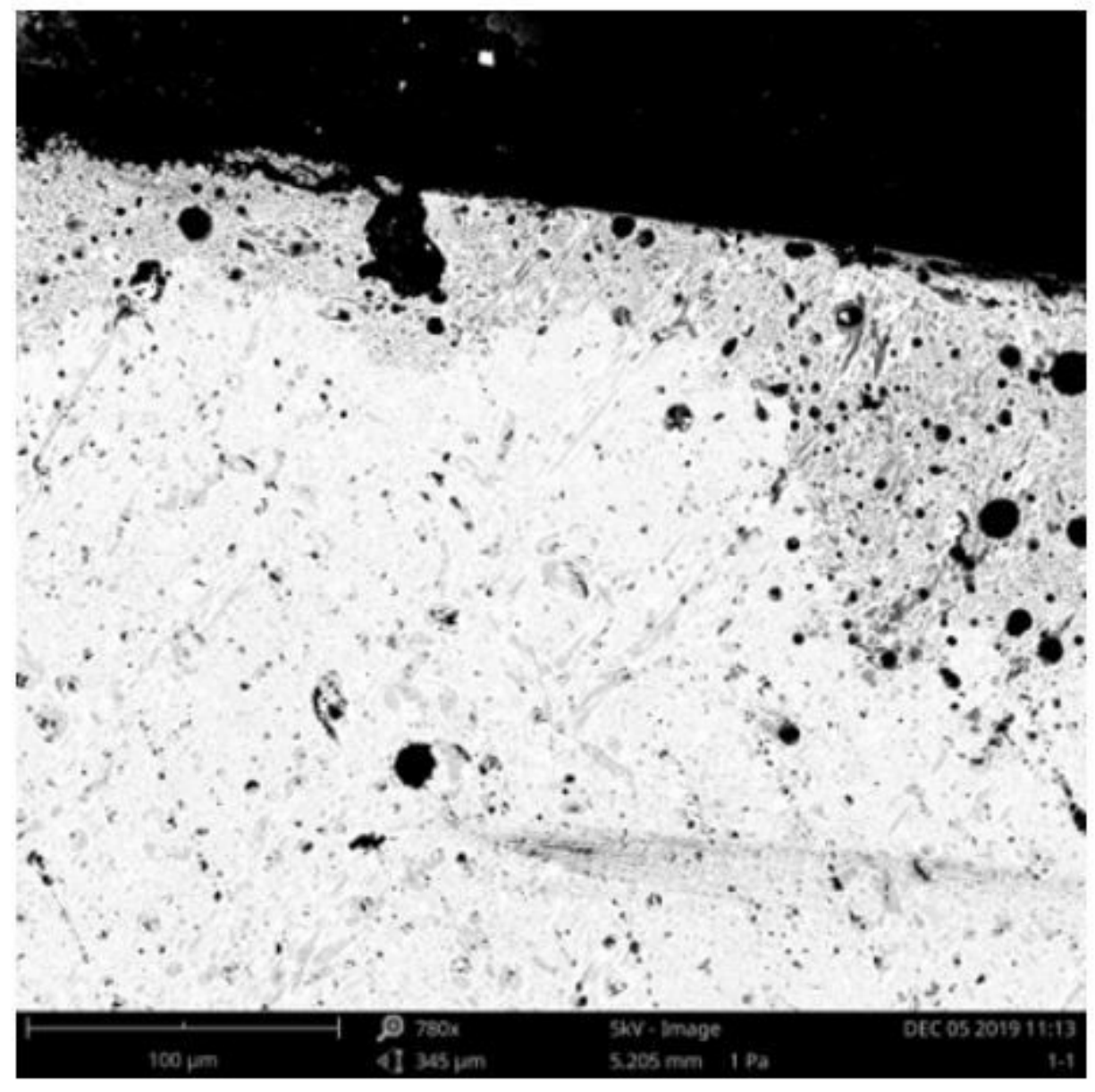

Figure 10

the arrangement of shrinkage cavities along the interface 